\title{
SEMI-RIGID ELASTO-PLASTIC POST BUCKLING ANALYSIS OF A SPACE FRAME WITH FINITE ROTATION
}

\author{
K.S. Lee ${ }^{1}$ and S.E. $\operatorname{Han}^{2, *}$ \\ ${ }^{1}$ Research Assistant Professor, Department of Architectural Engineering, \\ Inha University, 253 Yonghyundong, Nam-gu, Incheon, 402-751, South Korea \\ 2 Professor, Department of Architectural Engineering, \\ Inha University, 253 Yonghyundong, Nam-gu, Incheon, 402-751, South Korea \\ *(Corresponding author : E-mail: hsang@inha.ac.kr)
}

Received:4 December 2010; Revised: 17 January 2011; Accepted: 24 January 2011

\begin{abstract}
In this study, large-deformation and small-strain elasto-plastic analysis of space frames with symmetric cross sections and semi-rigid connections are presented. The effect of axial forces on the bending moment and lateral buckling are included. However, axial-torsional and warping effects are omitted. The Eulerian equations for a beam-column with finite rotation taking into account bowing effects are adopted for an elastic system and are extended to an inelastic system with a plastic hinge concept. The derived tangent stiffness matrix is asymmetric due to the finite rotation. The joint connection elements were introduced for semi-rigidity using a static condensation technique. The arc-length method was applied to trace the post-buckling range of elastic and elasto-plastic problems with semi-rigid connections. Nonlinear buckling and elasto-plastic collapse analyses were carried out for the proposed space frame to demonstrate the potential of the developed method in terms of accuracy and efficiency.
\end{abstract}

Keywords: Space frame, Large deformation, Beam-column, Plastic hinge, Semi-rigid

\section{INTRODUCTION}

Commonly, steel frames are analyzed and designed assuming ideal rigid joint or pin joint connections, however, testing shows that the connection behavior is semi-rigid. Hence, there may be problems or differences with the conventional design and analysis approach compared to the actual structural behavior. The structural post-buckling response of a semi-rigid space frame in the collapsed regime of deformation is still challenging and is an interesting area for analysis and structural design.

General theoretical formulations and computational algorithms have been developed for planer and space frames. Both a beam-column approach, based on the member's basic force and deformation relationships [1-17], and a finite element approach [18-60] have been used in developing the nonlinear governing equations. The cubic Hermite element is a finite element formulation that uses an energy principle and assumed shape functions for the displacement fields. This simple method for developing a nonlinear formulation for a space frame is widely used [18-29]. The large-deformation geometrically nonlinear analysis is carried out by various methods of treatment of the non-vectorial nature of rotations, the selection of coordinate systems of the stress-strain tensor and the linearization of variational equations. Large rotations are usually represented by Euler's finite theory [30,38] and applied to both beam-column and finite element theory. Agyris et al. [30-34] introduced so-called semi-tangential rotations to circumvent the non-vectorial or non-commutative behavior of successive finite rotations about fixed axes. A total or updated Lagrangian method by degenerated continuum equations is developed [35,36]. Some formulations are derived directly from the weak form of nonlinear rod-type equations by introducing appropriate kinematics [37-46]. The model is often called the 'geometrically exact finite-strain beam theory', and many modern finite element developments of three-dimensional beam theories based their approach on the so-called geometrically exact beam theory [37,38]. An alternative way of deriving efficient non-linear finite element models is the co-rotational approach [47-54]. The main idea of 
this approach is to decompose the motion of the element into rigid body and pure deformational parts through the use of a reference system that continuously rotates and translates with the element. The procedure for the co-rotational approach is similar to the Eulerian finite rotation of a beam-column element [3,9-15]. Izzuddin [55] adopted the Eulerian approach for large displacement analysis of thin-walled frames. Most of these finite element nonlinear analysis techniques are based on assumed displacement fields and require a large number of elements to model a structure with large deformation. There are some mixed hybrid elements for the objective of using one element to model each member [56-58] that are based on the complementary energy principle and abandon the assumed displacement shape for an element. There are also stress-based Cauchy formulations $[59,60]$.

The material nonlinearity in a space frame has been described by means of plastic hinge (concentrated or lumped) [4-6,9-11,16-17,21-23,57,58] and plastic zone (distributed or spread of plasticity) [34,46,54,61-66] models. In the plastic hinge approach, the effect of the material yielding is concentrated or lumped into a dimensionless plastic hinge located at the end of the member. There are fewer required elements in this approach, and it eliminates the integration process on the cross-section for each member. The plastic hinge approach requires less computational effort and is less costly than the plastic zone analysis. However, the nonlinear material laws are valid only for limited specific geometries of the cross section. In the case of the plastic zone model, the member needs to be subdivided into several elements along its length and cross-section to model the material nonlinearity. In the literature, the material nonlinearity is often evaluated at a fixed number of cross sections, or moment-curvature-thrust relations $[22,61]$ are derived for each cross-section.

Usually, the joint flexibilities of semi-rigid components are installed by the zero length spring connection element at the end of member [4-6,17,58,67-71]. A procedure of static condensation is used to asses the effect on the element stiffness matrix and equivalent nodal forces. The minimized number of elements in the space frame is required to evaluate the semi-rigidity. Therefore, the one-element-per-member approach is usually used in the semi-rigid analysis of space frame formulation in elastic or elasto-plastic analysis.

Studies that consider nonlinear semi-rigid connection properties in steel frames have been successfully conducted by many researchers. Studies by Chen and coworkers [4-6] are representative work in this area. In his research, he and his coworkers have performed semi-rigid elasto-plastic analysis with the plastic hinge concept for beam-column elements.

Kato et al. [67,68] carried out semi-rigid elasto-plastic analysis of three-dimensional (3D) steel reticulated domes using semi-rigid and elasto-plastic springs located at both ends and at mid-span for each 3D beam-column element in conjunction with an updated Lagrangian formulation.

Recently, Liu et al. [69] and Sekulovic [70] performed the inelastic semi-rigid analysis in static and dynamic case. Chiorean [71] performed the inelastic and large deflection analysis of steel space frames with non-linear flexible joint connections. However, these formulations were based on two-dimensional plane frames or small deformation theory, thereby assuming small member chord rotations and not considering the effect of finite rotation and bowing for large deformations in beam-column element formulations.

In this paper, a method for large deformational post-buckling analysis of semi-rigid elasto-plastic space frames is presented. To develop a space frame element that reflects the rigid body motion and relative deformation are calculated according to the theory of Spiller [12] and Levy and Spiller [15] for Eulerian finite rotation of a 3D space frame. The elastic beam-column formulations of 
Kassimali and Abbasnia [8] are also adopted. For the material nonlinearity, the equation for a lumped plastic hinge concept on a beam-column Abbasnia and Kassimali [11] is included. The effects of axial force on the member bending moment (bowing effect) in the elastic and plastic moment capacity are included in the analysis. The asymmetric geometric stiffness matrix, derived by Spiller [12], is used to include some buckling mechanisms of lateral buckling in physical situations. Additionally, the elastic semi-rigid connection spring formulation with the element static condensation procedure developed by Kato et al. [67,68] is adopted to represent the proper semi-rigid joint connection characteristics of beam-column elements. However, the effect of axial force on the member's torsional stiffness (Wagner effect) and warping effect are omitted for simplicity. Finally, nonlinear elastic, plastic beyond limit, or critical point analyses were performed using the arc-length method [72-75]. Analysis of numerical examples for nonlinear elastic and plastic analysis were carried out for the proposed simple and efficient space frame element with a joint connection element to demonstrate accuracy and efficiency.

\section{EULERIAN FORMULATION FOR FINITE ROTATION}

In the nonlinear analysis of space frames, the assumption that rotations of a body are additive has been widely adopted by researchers in updating the end rotations of frame elements at each incremental step. Such an assumption remains valid only for incremental steps with small rotations. For the cases with finite rotations, it is necessary to consider the non-commutative nature of rotations in three dimensions, such as post-buckling or bifurcation, which makes these space frames more difficult to analyze than trusses or plane frames in nonlinear analysis. In this paper, we used the previous work of Spiller [12] and Levy and Spiller [15] for the Eulerian finite rotation of 3D space frames, which is briefly described as follows.

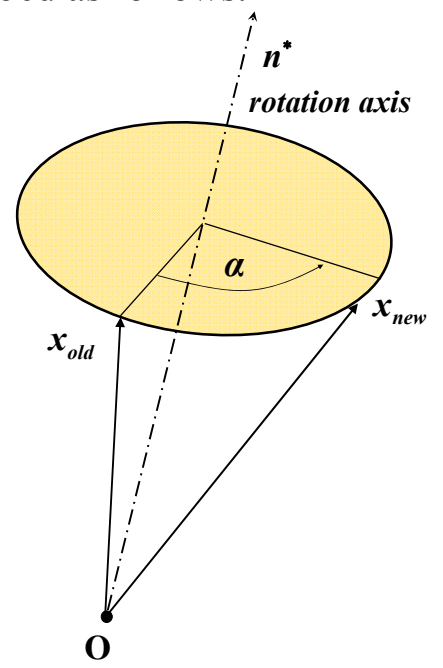

Figure 1. Rotation about an Axis

If an old position $\mathbf{x}_{\text {old }}$ of a body is rotated to new position $\mathbf{x}_{\text {new }}$, Euler's Theorem of rigid body motions implies that any finite rotation (or sequence of rotations) can be described as a single rotation $\alpha$ about some fixed axis described by a unit vector, $\mathbf{n}^{*}=\left\{n_{1}^{*}, n_{2}^{*}, n_{3}^{*}\right\}$, as shown in Figure 1. The new position vector $\mathbf{x}_{\text {new }}$ is described by the old position vector $\mathbf{x}_{\text {old }}$, the rotation $\alpha$ and the fixed axis unit vector $\mathbf{n}^{*}$ as follows:

$$
\mathbf{x}_{\text {new }}=\mathbf{x}_{\text {old }}-(1-\cos \alpha)\left\{\mathbf{x}_{\text {old }}-\left(\mathbf{x}_{\text {old }} \mathbf{n}^{*}\right) \mathbf{n}^{*}\right\}+\sin \alpha\left(\mathbf{n}^{*} \times \mathbf{x}_{\text {old }}\right)
$$


We can obtain the following matrix representation of finite rotations:

$\mathbf{x}_{\text {new }}=\widetilde{\mathbf{R}} \mathbf{x}_{\text {old }}$

$\mathbf{x}_{\text {old }}=\mathbf{R} \mathbf{x}_{\text {new }} \quad(\mathbf{R} \widetilde{\mathbf{R}}=\mathbf{I})$

where $\mathbf{R}$ is the rotation matrix in terms of the $\alpha$ and the components of $\mathbf{n}^{*}$ as follows:

$\widetilde{\mathbf{R}}=\left[\begin{array}{ccc}\cos \alpha+\mu n_{1}^{2} & -n_{3} \sin \alpha+\mu n_{1} n_{2} & n_{2} \sin \alpha+\mu n_{1} n_{3} \\ n_{3} \sin \alpha+\mu m_{1} n_{2} & \cos \alpha+\mu m_{2}^{2} & -n_{1} \sin \alpha+\mu n_{2} n_{3} \\ -n_{2} \sin \alpha+\mu n_{1} n_{3} & n_{1} \sin \alpha+\mu n_{2} n_{3} & \cos \alpha+\mu n_{3}^{2}\end{array}\right]$

with $\mu=1-\cos \alpha$.

Based on Euler's finite rotation formula, the rotation matrix is necessary to describe both joint rotations and member rigid body rotations. The matrix can be derived from the so-called Rodriguez rotation vector, a rotation about a fixed axis represented by a unit vector, and a scalar angle of rotation. Thus, a 3D rotation can be represented by a vector-like entity, but such entities cannot be added like vectors. Furthermore, it is assumed that these vector-like entities possess Taylor series expansions whose increments are the small rotation vectors of linear structural analysis $[12,15]$. To separate the large rigid body deformations of a member from its relative deformations, which are assumed to be small, a Eulerian or local member coordinate system was used, as shown in Figure 2.
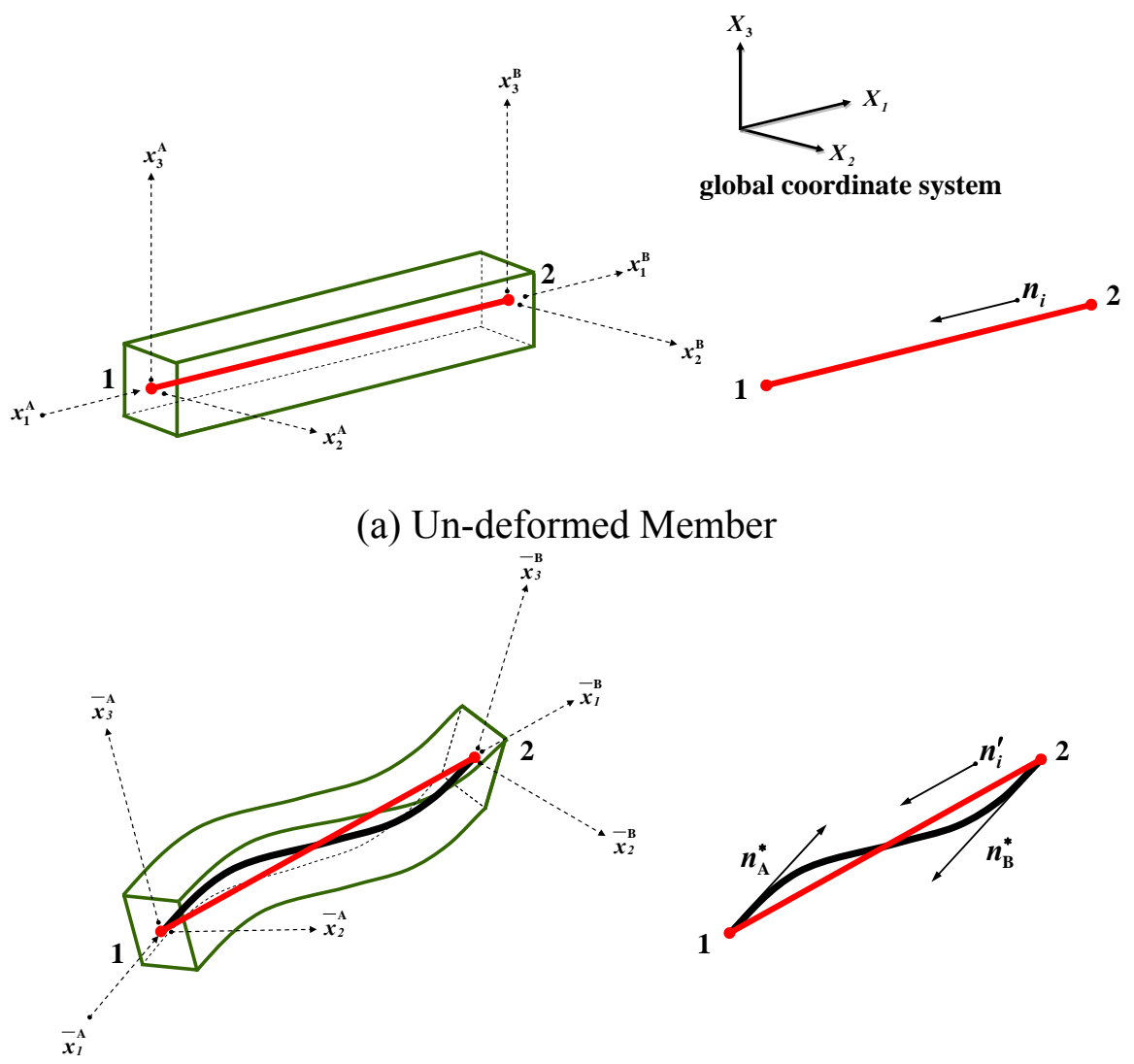

(b) Deformed Member

Figure 2. Relative Member Deformations 
In Figure 2, the unit vector of the non-deformed member axis is $\mathbf{n}_{i}$, and the unit vector of the deformed member axis is $\mathbf{n}_{i}^{\prime}$.

Furthermore, the unit vectors of the deformed member axis at joints 1 and $2, \mathbf{n}_{1}^{*}$ and $\mathbf{n}_{2}^{*}$, can be represented by Euler's joint rotation matrices, $\mathbf{R}_{1}$ and $\widetilde{\mathbf{R}}_{2}$. The unit vector of the non-deformed member axis, $\mathbf{n}_{i}$, can be represented as follows.

$$
\begin{aligned}
& \mathbf{n}_{1}^{*}=\widetilde{\mathbf{R}}_{1} \mathbf{n}_{i} \\
& \mathbf{n}_{2}^{*}=\widetilde{\mathbf{R}}_{2} \mathbf{n}_{i}
\end{aligned}
$$

The rotation vector at joint $2, \theta_{2}$, can be represented by the cross product of the member unit vector, $\mathbf{n}_{i}$, and the deformed member unit vector, $\mathbf{n}_{2}^{*}$, at joint 2 with properties as follows:

$$
\begin{aligned}
& \theta_{2} \cong \mathbf{n}_{i} \times \mathbf{n}_{2}^{*} \\
& \left|\theta_{2}\right|=\cos ^{-1}\left(\mathbf{n}_{i} \mathbf{n}_{2}^{*}\right)
\end{aligned}
$$

The end of member rotation vector for joint $1, \theta_{1}$, is represented as follows:

$$
\theta_{1}=\theta_{2}+\theta_{12}
$$

where $\theta_{12}$ is the rotation of joint 1 with respect to joint 2 . This equation simply describes the vector form of the matrix product, $\mathbf{R} \widetilde{\mathbf{R}}_{2}$.

From this simple and exact formulation of Euler's finite rotation [12,15], we can calculate the exact member end rotations, $\theta_{1}, \theta_{2}$ which is separated the rigid body rotations. In the case of geometrically nonlinear large displacement analysis of space frame, the exact member rotational deformation is relatively small, because of its large rigid body rotation occurrence. The formulation of this study is valid for the elastic, elasto-plastic large deformation analysis of space frame element with beam-column equations. The accuracy and efficiency are demonstrated in verification examples lately.

\section{ELASTIC SPACE FRAME ELEMENT}

To analyze the plastic collapsing and post-buckling of the space frame, one should include the formulation of a large deformational effect. In this study, the beam-column element with a bowing effect $[3,8,9]$ was used as the basic element equation, and then those $2 \mathrm{D}$ beam-column element equations were expanded to incorporate the element tangent stiffness matrix. The direct 3D beam-column elements that account the lateral-torsional effect are described in the literature [13-15]; however, these formulations are too complex for the elasto-plastic post-buckling analysis of a semi-rigid space frame. Therefore, in this study, the well-known two-dimensional (2D) beam-column equations are adopted for numerical efficiency. The coupling effect of the member axial-torsional and warping effects are omitted. 


\subsection{Beam-column Equation}

The member force of the space frame element shown in Figure 3 can be written by the 2D beam-column equations $[3,8,9]$, which include the effect of member displacement upon the bending moment to the end. As a result, the member stiffness becomes a function of the axial load.

$$
\begin{aligned}
& M_{1 j}=\frac{E I_{j}}{L}\left(c_{1 j} \theta_{1 j}+c_{2 j} \theta_{2 j}\right) \quad(j=2,3) \\
& M_{2 j}=\frac{E I_{j}}{L}\left(c_{2 j} \theta_{1 j}+c_{1 j} \theta_{2 j}\right) \quad(j=2,3) \\
& M_{t}=\frac{G J}{L} \varphi_{t} \\
& Q=E A\left(\frac{u}{L}-\sum_{j=2}^{3} c_{b j}\right) \\
& C_{b j}=b_{1 j}\left(\theta_{1 j}+\theta_{2 j}\right)^{2}+b_{2 j}\left(\theta_{1 j}-\theta_{2 j}\right)^{2}
\end{aligned}
$$

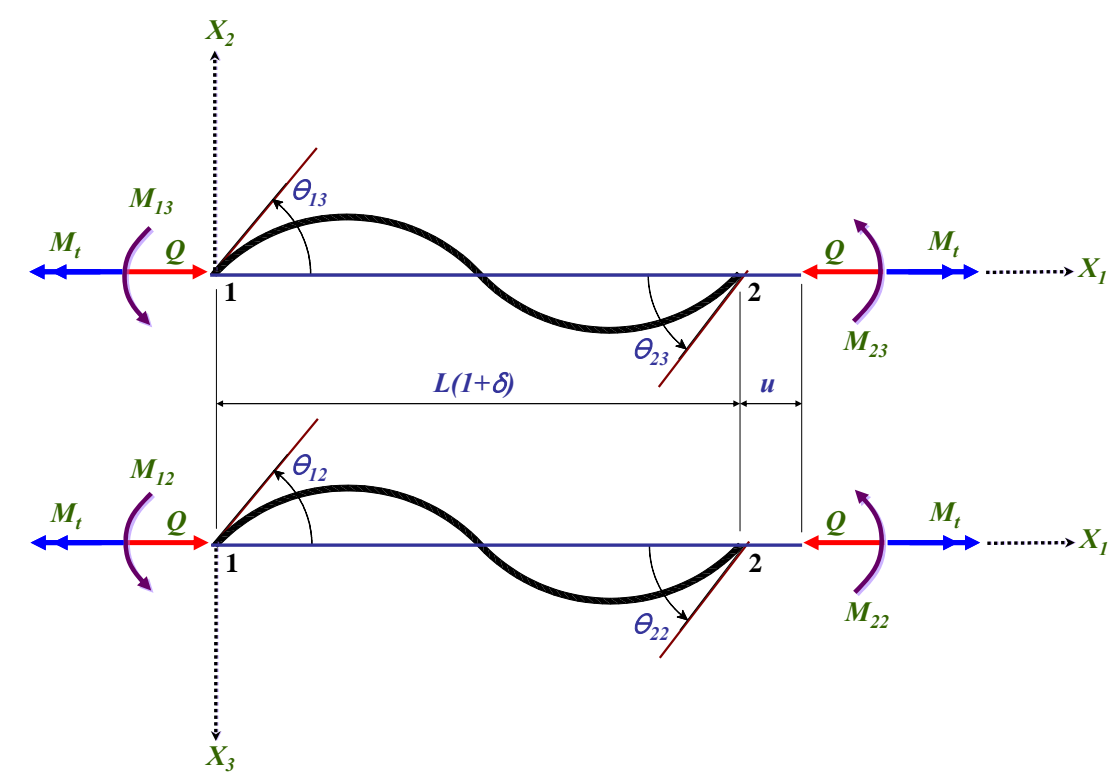

Figure 3. Relative Member Deformations and Corresponding Forces

As is shown in Figure 3, $\theta_{1 j}$ and $\theta_{2 j}$ are the relative member end rotations calculated by Eqs. 7 and 9, where $\varphi_{t}$ is linear axial twist, $u$ is axial displacement, $A$ is the area of cross section, $E$ is the modulus of elasticity, $I_{j}$ is the moment of inertia about the $X_{j}$-axis, GJ is the torsional rigidity, $c_{1 j}$ and $c_{2 j}$ are the stability functions for bending about the $X_{j}$-axis, $c_{b j}$ is the length correction factor caused by flexural deformation (bowing) about the $X_{j}$-axis, and $b_{1 j}$ and $b_{2 j}$ are the bowing functions of the axial force parameter $q$, defined in Eq. 15.

$$
q=\frac{Q}{Q_{\text {Euler }}}=Q \frac{L^{2}}{\pi^{2} E I_{j}}
$$

The expression for the member axial force, $Q$ in Eq. 13 contains bowing functions $b_{1 j}$ and $b_{2 j}$, which are functions of the axial force parameter, $q$. Therefore, Eq. 13 is a nonlinear function. A computational difficulty arises in determining $Q$ from the axial displacement, $u$. An iterative 
procedure must be employed to compute the axial force of a member and can be solved using the following process.

Noting that $q$ is the only unknown quantity in Eq. 13, let a new function, $K(q)$, be defined as follows:

$$
K(q)=\frac{\pi^{2}}{\lambda^{2}} q+\sum_{j=2}^{3} c_{b j}-\frac{u}{L}=0
$$

A new value of $q_{i+1}$ is obtained from the first order Taylor series expansion,

$$
q_{i+1}=q_{i}+\Delta q_{i}=q_{i}-\frac{K\left(q_{i}\right)}{K^{\prime}\left(q_{i}\right)}
$$

where $K^{\prime}(q)$ is the derivative of $K(q)$ with respect to the axial force parameter, $q$, and represented as follows:

$$
K^{\prime}(q)=\frac{d K(q)}{d q}=\frac{\pi^{2}}{\lambda^{2}}+\sum_{n=2,3}^{3} \frac{1}{\varepsilon_{j}}\left\{b_{1 j}^{\prime}\left(\theta_{1 j}+\theta_{2 j}\right)^{2}+b_{2 j}^{\prime}\left(\theta_{1 j}-\theta_{2 j}\right)^{2}\right\}
$$

where $\lambda=L / \sqrt{I / A}$ and $\varepsilon_{j}=I_{j} / I$, in which $I$ is an arbitrary reference moment of inertia and $b_{i j}^{\prime}$ is a differentiation of the bowing function with respect to $q$. An approximate solution to this equation for $q_{i}$ is initially assumed, and the iteration is performed until $\left|\Delta q_{i}\right|$ is sufficiently small. After determining the axial force $Q$ by the iterative process, member end moments were computed from Eqs. 10-12. A detailed description of Eqs. 10-18 and the corresponding variables are explained in references $[3,8,9]$.

\subsection{Approximate Beam-Column Equation}

Computational difficulties are occasionally encountered in post-buckling analysis when the closed form of the stability and bowing functions and their derivatives become singular at $q=0$. The explicit expressions for the stability function, $c_{1 j}$ and $c_{2 j}$, and the bowing function, $b_{1 j}$ and $b_{2 j}$, in terms of the axial force parameter $q$ can be written as a series expression [9]. By using the following series expressions, these difficulties can be avoided. However, these equations are only theoretically valid for low absolute values of axial force.

$$
\begin{aligned}
& c_{1 j} \cong 4-\frac{4}{15} \pi^{2} q-\frac{11}{6300} \pi^{4} q^{2}-\frac{1}{27000} \pi^{6} q^{3} \\
& c_{2 j} \cong 2+\frac{1}{30} \pi^{2} q+\frac{13}{12600} \pi^{4} q^{2}+\frac{11}{378000} \pi^{6} q^{3} \\
& b_{1 j} \cong \frac{1}{40}+\frac{1}{2800} \pi^{2} q+\frac{1}{168000} \pi^{4} q^{2}+\frac{11}{388080000} \pi^{6} q^{3} \\
& b_{2 j} \cong \frac{1}{24}+\frac{1}{720} \pi^{2} q+\frac{1}{20160} \pi^{4} q^{2}+\frac{11}{604800} \pi^{6} q^{3}
\end{aligned}
$$


The approximate beam-column equation can be obtained by substituting Eqs. 19-22 for the member force equations Eqs. 10-13.

By substituting Eq. 19 and 20, the member force equation of the approximate beam-column equation can be obtained as follows:

$$
\begin{aligned}
& M_{1 j}=\left(\frac{4 E I_{j}}{L}+\frac{2 Q L}{15}\right) \theta_{1 j}+\left(\frac{2 E I_{j}}{L}-\frac{Q L}{30}\right) \theta_{2 j} \quad(j=2,3) \\
& M_{1 j}=\left(\frac{2 E I_{j}}{L}-\frac{Q L}{30}\right) \theta_{1 j}+\left(\frac{4 E I_{j}}{L}+\frac{2 Q L}{15}\right) \theta_{2 j} \quad(j=2,3) \\
& M_{t}=\frac{G J}{L} \varphi_{t} \\
& Q=E A\left\{\frac{u}{L}+\frac{1}{30}\left(2 \theta_{12}^{2}-\theta_{12} \theta_{22}+2 \theta_{22}^{2}\right)+\frac{1}{30}\left(2 \theta_{13}^{2}-\theta_{13} \theta_{13}+2 \theta_{13}^{2}\right)\right\}
\end{aligned}
$$

Teh [52] called the finite element formulated beam element that used the approximate beam-column equation as co-rotational cubic element. And these formulations were used in some references $[47,48]$. Though, this expression is an approximated expression of the closed form of Eqs. 10-13, it has shown satisfying results compared to a beam-column element with one element per member [47] or two elements per member [48] with a symmetric tangent stiffness matrix and joint rotation matrix. Lately, several formulations have been proposed in the literature [52,76-79] to improve the shortcomings of the cubic element and the conventional stability-based beam-column element. The improved formulation of co-rotational cubic elements by Teh and Clarke [52] used the asymmetric tangent stiffness matrix and shows more accurate results. Liew et al. [79] used the symmetric portion of the induced moment matrix alone, which is referred to as the joint moment matrix and needs to be assembled to form the structure tangent stiffness matrix.

\subsection{Tangent Stiffness Matrix for Large Deformation}

In this study, the beam-column approach in section 3.1 is applied to elastic and elasto-plastic post-buckling problems, and the so-called approximate beam-column element in section 3.2, which is similar to the formulation of the co-rotational form of cubic element, is applied to the analysis of elastic problems alone. The non-commutative nature of finite rotation in section 2 yields an asymmetric tangent stiffness matrix in both cases.

The member force-deformation relationships of Eqs. 10-13 may be rewritten as follows:

$$
\begin{aligned}
& \mathbf{S}^{T}=\left\{Q, M_{t}, M_{12}, M_{13}, M_{22}, M_{23}\right\} \\
& \overline{\mathbf{u}}^{T}=\left\{u, \varphi_{t}, \theta_{12}, \theta_{13}, \theta_{22}, \theta_{23}\right\}
\end{aligned}
$$

And the incremental form of the member equation is written as follows:

$$
\Delta \overline{\mathbf{s}}=\mathbf{t} \Delta \overline{\mathbf{u}}
$$

Where $t$ is the element stiffness matrix according to the incremental member displacement $\Delta \overline{\mathbf{u}}$ in the local coordinates, as shown previously in Eqs. 10-13 and 23-26. By using the incidence matrix $\overline{\mathbf{B}}$, the element nodal force and nodal displacement can be written as follows: 
$\overline{\mathbf{d}}=\overline{\mathbf{B}} \overline{\mathbf{u}}$

$\overline{\mathbf{f}}=\overline{\mathbf{B}} \overline{\mathbf{s}}$

Conventionally, the element nodal force in global coordinates $\mathbf{F}$ can be written from the rotation matrix $\mathbf{R}$ :

$\mathbf{F}=\mathbf{R} \overline{\mathbf{f}}=\mathbf{R} \overline{\mathbf{B}} \overline{\mathbf{s}}$

Eq. 32 could be interpreted as a member equilibrium equation in a global coordinate system. The tangent stiffness matrix of the beam-column can be obtained from the differential form with respect to the incremental displacement $[12,15]$ :

$$
\begin{aligned}
& \Delta \mathbf{F}=\Delta(\mathbf{R} \overline{\mathbf{B}} \overline{\mathbf{s}})=\mathbf{R} \overline{\mathbf{B}}(\Delta \overline{\mathbf{s}})+\mathbf{R}(\Delta \overline{\mathbf{B}}) \overline{\mathbf{s}}+(\Delta \mathbf{R}) \overline{\mathbf{B}} \overline{\mathbf{s}} \\
& =\left(\mathbf{K}_{E}+\mathbf{K}_{G}^{S}+\mathbf{K}_{G}^{R}\right) \delta \mathbf{d}
\end{aligned}
$$

The first term in Eq. 33 becomes the elastic stiffness matrix. The second and third terms become the geometric stiffness matrix. $\mathbf{K}_{G}^{S}$ and $\mathbf{K}_{G}^{R}$ indicate the stretching and rotational terms of the geometric stiffness. The rotational geometric stiffness matrix, $\mathbf{K}_{G}^{R}$, is asymmetric [12,15] due to the non-commutative nature of finite rotation, and this geometric stiffness matrix is responsible for the lateral-torsional buckling and the buckling mode shape at the critical point (limit or bifurcation). However, the geometric stiffness matrix does little to affect the material nonlinear problems.

\section{INELASTIC EFFECT}

The plastic hinge concept was applied to account for the material nonlinearity. The material was assumed to be ideally elasto-plastic without strain-hardening or unloading effects. The yielding is concentrated at the member's ends in the forms of plastic hinges.

The members were assumed to remain elastic between plastic hinges with the large deformation formulation as mentioned in the previous section, and the yielding criterion [11] of the plastic hinge assumed to be as follows:

$g_{n}=\left[\left(\frac{\bar{M}_{t}}{M_{p 1}}\right)^{2}+\sum_{j=2}^{3}\left(\frac{\bar{M}_{i j}}{M_{p j}}\right)^{2}\right]^{0.5}+\left(\frac{\bar{Q}}{Q_{y}}\right)^{2}=1 \quad(i=1,2 \quad j=2,3)$

where $Q_{y}, M_{p 1}$ and $M_{p j}$ are the axial yielding force, the plastic torsional moment capacity in the absence of axial force and bending moments, and the uniaxial plastic moment capacity for bending about the $X_{j}$-axis, respectively. $\bar{Q}, \bar{M}_{t}$ and $\bar{M}_{i j}$ are the axial force, torsional moment and moment at end $i$ about the $X_{j}$-axis when the plastic hinge forms, respectively.

When plastic hinges are present, the member end rotations at the released ends are obtained from the relative member force-deformation relationships instead of the orientation matrices of the adjacent joints [11]. In each of the foregoing cases, the relative twisting of the member ends is given as follows: 
$\varphi_{t}=\frac{L \bar{M}_{t}}{G J}$

Eq. 35 performs an important role in plastic analysis when the torsional moment governs the structural behavior, such as in Example 6.4, a horizontal bent frame.

A more comprehensive explanation and numerical results are discussed below. As explained above, the axial force and bending moment are coupled when beam-column equations are employed, and the member end release effect may occur and influence the member equilibrium when the plastic hinges occur. Therefore, the iterative procedures of Eqs. 16-17 are required with the modification of Eq. 18, which accounts for the release end effect by the following equation:

$$
\begin{aligned}
& K^{\prime}(q)=\frac{\pi^{2}}{\lambda^{2}}+\sum_{j=2}^{3} c_{b j}^{\prime} \\
& c_{b j}^{\prime}=b_{1 j}^{\prime}\left(\theta_{1 j}+\theta_{2 j}\right)^{2}+b_{2 j}^{\prime}\left(\theta_{1 j}-\theta_{2 j}\right)^{2}+2 b_{1 j}\left(\theta_{1 j}+\theta_{2 j}\right)\left(\theta_{1 j}^{\prime}+\theta_{2 j}^{\prime}\right) \\
& +2 b_{1 j}\left(\theta_{1 j}-\theta_{2 j}\right)\left(\theta_{1 j}^{\prime}-\theta_{2 j}^{\prime}\right) \quad(j=2,3)
\end{aligned}
$$

\section{SEMI-RIGID CONNECTION ELEMENT}

To consider the semi-rigid connection characteristics of member ends, the elastic connection spring formulation of Kato [67] was adopted as shown in Figure 4. The overall stiffness matrix of the compound element can be computed with the static condensation technique.

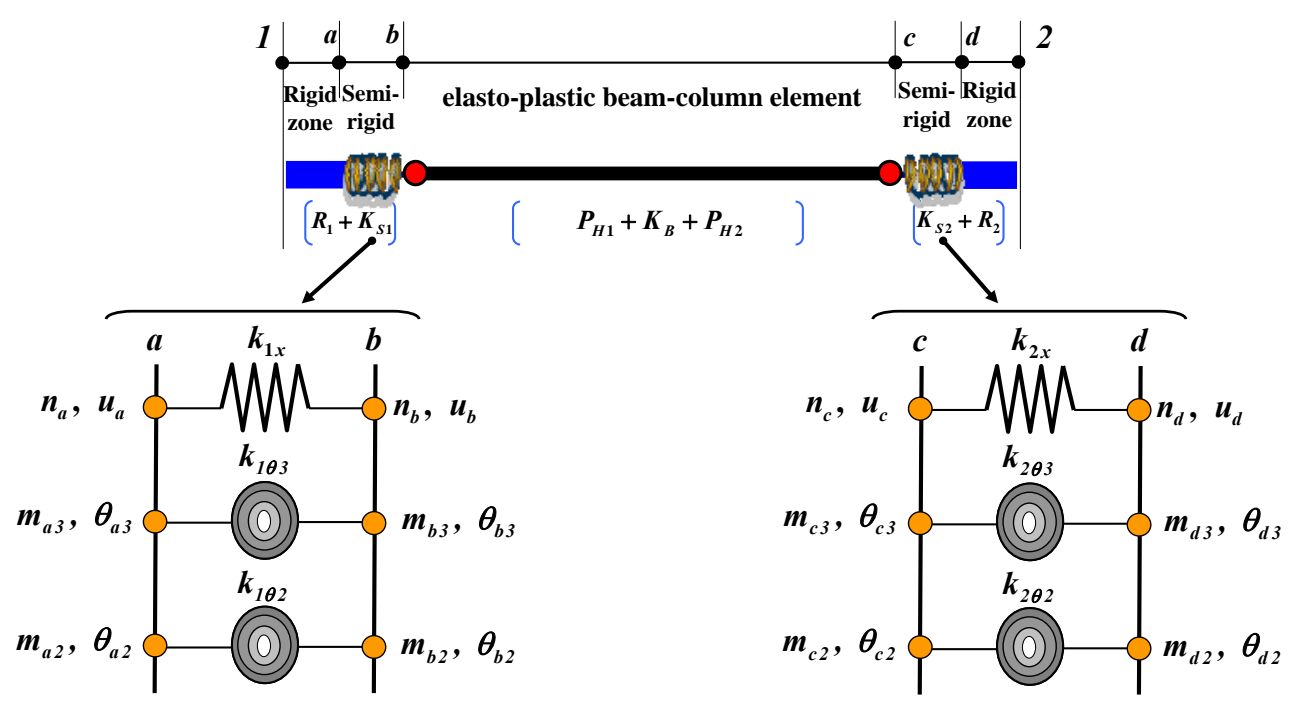

Figure 4. Semi-rigid Connection Spring Element

The member is modeled to be composed of the elements in the order as follows: (1) a rigid panel element of (1-a); (2) an elastic spring $\left(K_{s 1}\right)$ to represent the left end semi-rigid joint connection(a-b); (3) an elastic beam-column element $\left(K_{B}\right)$ between nodes b and c to include the large deformation behavior of the member with plastic hinges $\left(P_{H 1}, P_{H_{2}}\right)$ (b-c); (4) an elastic spring $\left(K_{s 2}\right)$ to represent the left end semi-rigid joint connection (c-d); and (5) a rigid panel element (d-2). 
Equilibrium equations for elastic springs, denoted by a-b and c-d at both ends of each member, can be given by specific kinematics for outer and inner nodes. At the left connection a-b with $K_{s 1}$, for example, the relationship of force-deformation can be written as follows:

$$
\begin{aligned}
& n_{b}=-n_{a}=k_{1 x}\left(u_{b}-u_{a}\right) \\
& m_{b 2}=-m_{a 2}=k_{1 \theta 2}\left(\theta_{b 2}-\theta_{a 2}\right) \\
& m_{b 3}=-m_{a 3}=k_{1 \theta 3}\left(\theta_{b 3}-\theta_{a 3}\right)
\end{aligned}
$$

Where $u_{a}, \theta_{a 2}, \theta_{a 3}$ and $u_{b}, \theta_{b 2}, \theta_{b 3}$ are the axial displacements and the rotations about the $X_{j}$-axes, respectively. The elastic constants, $k_{1 x}, k_{1 \theta 2}$ and $k_{1 \theta 3}$, are the axial rigidity and the bending rigidities of the spring, $\mathbf{K}_{s 1}$. Thus, the matrix form of Eq. 38 is as follows:

$$
\left\{\begin{array}{c}
n \\
m_{2} \\
m_{3}
\end{array}\right\}=\mathbf{K}_{s 1}\left\{\begin{array}{c}
u \\
\theta_{2} \\
\theta_{3}
\end{array}\right\}=\left[\begin{array}{ccc}
k_{1 x} & 0 & 0 \\
0 & k_{1 \theta 2} & 0 \\
0 & 0 & k_{1 \theta 2}
\end{array}\right]\left\{\begin{array}{c}
u_{b}-u_{a} \\
\theta_{b 2}-\theta_{a 2} \\
\theta_{b 3}-\theta_{a 3}
\end{array}\right\}
$$

Usually, the elastic constants, $k_{1 x}, k_{1 \theta 2}$ and $k_{1 \theta 3}$ of the spring $\mathbf{K}_{s 1}$ would be determined by experimentation or with a previously proposed model [5].

The extended form of Eq. 39 for 12-dof of the spring end node a-b can be written as follows:

$$
\mathbf{F}_{a b}=\mathbf{K}_{s 1} \mathbf{d}_{a b}
$$

Where the force and displacement vectors $\mathbf{F}_{a b}, \mathbf{d}_{a b}$ and spring stiffness matrix $\mathbf{K}_{s 1}$ are written as follows:

$$
\begin{aligned}
& \mathbf{F}_{a b}=\left\{n_{a 1}, q_{a 2}, q_{a 3}, m_{a 1}, m_{a 2}, m_{a 3}, n_{b 1}, q_{b 2}, q_{b 3}, m_{b 1}, m_{b 2}, m_{b 3}\right\}^{T} \\
& \mathbf{d}_{a b}=\left\{u_{a}, v_{a}, w_{a}, \theta_{a 1}, \theta_{a 2}, \theta_{a 3}, u_{b}, v_{b}, w_{b}, \theta_{b 1}, \theta_{b 2}, \theta_{b 3}\right\}^{T}
\end{aligned}
$$

$$
\mathbf{K}_{s 1}=\left[\begin{array}{cc}
\mathbf{K}_{s 1}^{*} & -\mathbf{K}_{s 1}^{*} \\
-\mathbf{K}_{s 1}^{*} & \mathbf{K}_{s 1}^{*}
\end{array}\right], \quad \mathbf{K}_{s 1}^{*}=\left[\begin{array}{cccccc}
k_{s 1} & 0 & 0 & 0 & 0 & 0 \\
0 & 0 & 0 & 0 & 0 & 0 \\
0 & 0 & 0 & 0 & 0 & 0 \\
0 & 0 & 0 & 0 & 0 & 0 \\
0 & 0 & 0 & 0 & k_{1 \theta 2} & 0 \\
0 & 0 & 0 & 0 & 0 & k_{1 \theta 3}
\end{array}\right]
$$

The stiffness matrix of member end node 1, 2 is represented from the rigid zone-spring displacement relationship matrix $b_{1}$ and $b_{2}$ for each end node 1 and 2, respectively:

$$
\mathbf{K}_{1}=\mathbf{b}_{1}^{T} \mathbf{K}_{s 1} \mathbf{b}_{1}, \quad \mathbf{K}_{2}=\mathbf{b}_{s}^{T} \mathbf{K}_{s s} \mathbf{b}_{s}
$$


Where $b_{1}$ and $b_{2}$ can be written as follows:

$$
\begin{aligned}
& \mathbf{b}_{1}=\left[\begin{array}{cc}
b_{11} & 0 \\
0 & b_{1 b}
\end{array}\right], \mathbf{b}_{11}=\left[\begin{array}{cccccc}
1 & 0 & 0 & 0 & 0 & 0 \\
0 & 1 & 0 & 0 & 0 & L_{1} \\
0 & 0 & 1 & 0 & -L_{1} & 0 \\
0 & 0 & 0 & 1 & 0 & 0 \\
0 & 0 & 0 & 0 & 1 & 0 \\
0 & 0 & 0 & 0 & 0 & 1
\end{array}\right], \mathbf{b}_{1 b}=\left[\begin{array}{cccccc}
1 & 0 & 0 & 0 & 0 & 0 \\
0 & 1 & 0 & 0 & 0 & 0 \\
0 & 0 & 1 & 0 & 0 & 0 \\
0 & 0 & 0 & 1 & 0 & 0 \\
0 & 0 & 0 & 0 & 1 & 0 \\
0 & 0 & 0 & 0 & 0 & 1
\end{array}\right] \\
& \mathbf{b}_{2}=\left[\begin{array}{cc}
\mathbf{b}_{2 d} & 0 \\
0 & \mathbf{b}_{22}
\end{array}\right], \mathbf{b}_{2 d}=\left[\begin{array}{cccccc}
1 & 0 & 0 & 0 & 0 & 0 \\
0 & 1 & 0 & 0 & 0 & 0 \\
0 & 0 & 1 & 0 & 0 & 0 \\
0 & 0 & 0 & 1 & 0 & 0 \\
0 & 0 & 0 & 0 & 1 & 0 \\
0 & 0 & 0 & 0 & 0 & 1
\end{array}\right], \quad \mathbf{b}_{22}=\left[\begin{array}{cccccc}
1 & 0 & 0 & 0 & 0 & 0 \\
0 & 1 & 0 & 0 & 0 & L_{2} \\
0 & 0 & 1 & 0 & -L_{2} & 0 \\
0 & 0 & 0 & 1 & 0 & 0 \\
0 & 0 & 0 & 0 & 1 & 0 \\
0 & 0 & 0 & 0 & 0 & 1
\end{array}\right]
\end{aligned}
$$

The incremental equilibrium equation of a composed member can be written (as follows) for each semi-rigid spring and beam-column element:

$$
\left[\begin{array}{ccc}
\mathbf{K}_{1} & 0 & 0 \\
0 & \mathbf{K}_{b} & 0 \\
0 & 0 & \mathbf{K}_{2}
\end{array}\right]\left\{\begin{array}{l}
\delta \mathbf{d}_{1} \\
\delta \mathbf{d}_{b} \\
\delta \mathbf{d}_{c} \\
\delta \mathbf{d}_{2}
\end{array}\right\}+\left\{\begin{array}{c}
\mathbf{g}_{1} \\
\mathbf{g}_{b}+\mathbf{F}_{b, \text { beam }} \\
\mathbf{F}_{c, \text { beam }}+\mathbf{g}_{c} \\
\mathbf{g}_{2}
\end{array}\right\}-\left\{\begin{array}{c}
\mathbf{P}_{1} \\
0 \\
0 \\
\mathbf{P}_{2}
\end{array}\right\}=0
$$

where the tangent stiffness matrix $\mathbf{K}_{b}$ and force vector at each end node of $\mathrm{b}$ and $\mathrm{c}, \mathbf{F}_{b, \text { beam }}$ and $\mathbf{F}_{c, \text { beam }}$, are the components of the elasto-plastic beam-column element with plastic hinges that were explained in the previous chapter, and $\mathbf{P}_{1}$ and $\mathbf{P}_{2}$ are the external load vector for each outer node, 1 and 2. Thus, $\mathbf{g}_{1}, \mathbf{g}_{b}, \mathbf{g}_{c}, \mathbf{g}_{2}$ are the semi-rigid spring force vectors and can be written as follows:

$$
\left\{\begin{array}{l}
\mathbf{g}_{1} \\
\mathbf{g}_{b}
\end{array}\right\}=\mathbf{b}_{1}^{T}\left\{\begin{array}{l}
\mathbf{F}_{1, s 1} \\
\mathbf{F}_{b, s 1}
\end{array}\right\}=\mathbf{b}_{1}^{T}\left\{\begin{array}{l}
\mathbf{F}_{a, s 1} \\
\mathbf{F}_{b, s 1}
\end{array}\right\}, \quad\left\{\begin{array}{l}
\mathbf{g}_{c} \\
\mathbf{g}_{2}
\end{array}\right\}=\mathbf{b}_{2}^{T}\left\{\begin{array}{l}
\mathbf{F}_{c, s 2} \\
\mathbf{F}_{2, s 2}
\end{array}\right\}=\mathbf{b}_{2}^{T}\left\{\begin{array}{l}
\mathbf{F}_{c, s 2} \\
\mathbf{F}_{d, s 2}
\end{array}\right\}
$$

The reassembled form of Eq. 47 for each inner $(b, c)$ and outer $(1,2)$ node is as follows:

$$
\begin{aligned}
& {\left[\begin{array}{cc}
\mathbf{A} & \mathbf{B} \\
\mathbf{B}^{T} & \mathbf{C}
\end{array}\right]\left\{\begin{array}{l}
\delta \mathbf{d}_{12} \\
\delta \mathbf{d}_{b c}
\end{array}\right\}+\left\{\begin{array}{l}
\mathbf{G}_{12} \\
\mathbf{G}_{b c}
\end{array}\right\}=\left\{\begin{array}{c}
\mathbf{P}_{12} \\
0
\end{array}\right\}} \\
& \delta \mathbf{d}_{12}=\left\{\begin{array}{l}
\delta \mathbf{d}_{1} \\
\delta \mathbf{d}_{2}
\end{array}\right\}, \quad \delta \mathbf{d}_{b c}=\left\{\begin{array}{l}
\delta \mathbf{d}_{b} \\
\delta \mathbf{d}_{c}
\end{array}\right\}
\end{aligned}
$$




$$
\mathbf{G}_{12}=\left\{\begin{array}{l}
\mathbf{g}_{1} \\
\mathbf{g}_{2}
\end{array}\right\}, \quad \mathbf{G}_{b c}=\left\{\begin{array}{l}
\mathbf{g}_{b}+\mathbf{F}_{b, \text { beam }} \\
\mathbf{F}_{c, \text { beam }}+\mathbf{g}_{c}
\end{array}\right\}, \quad \mathbf{P}_{12}=\left\{\begin{array}{l}
\mathbf{P}_{1} \\
\mathbf{P}_{2}
\end{array}\right\}
$$

From the static condensation procedure, the equilibrium equation of the composed element of Figure 4 can be written as follows:

$$
\mathbf{K} \delta \mathbf{d}_{12}=\mathbf{P}_{12}-\mathbf{F}
$$

Where

$$
\begin{aligned}
& \mathbf{K}=\mathbf{A}-\mathbf{B C}^{-1} \mathbf{B}^{T} \\
& \mathbf{F}=\mathbf{G}_{12}-\mathbf{B C}^{-1} \mathbf{G}_{b c}
\end{aligned}
$$

Figure 5 illustrates the various modeling capacities of the proposed semi-rigid, elasto-plastic beam-column element. The formulation of the proposed element was obtained from the previous, well-defined research of Spiller [12], Levy and Spiller [15], Kassimali and Abbasnia [8], Abbasnia and Kassimali [11] and Kato [67]. The numerical accuracy and capacity were verified by the following examples.
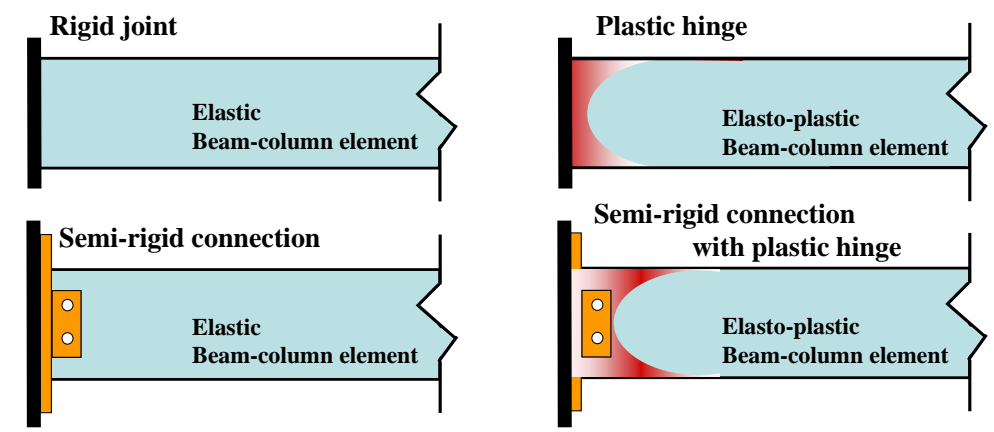

Figure 5. Various Modeling Capacities of the Proposed Element

\section{VERIFICATION EXAMPLES}

In an effort to assess the computational merits and limitations of the method of large deformation semi-rigid elasto-plastic analysis presented here, various numerical examples were solved with the proposed approach, and comparisons were made with previously published results. To trace the complete load-deflection curve, the arc-length method was adopted.

Examples 6.1 and 6.2 are presented to demonstrate the accuracy of the proposed beam-column element (section 3.1) and approximate beam-column element (section 3.2) in conducting large-deformational elastic post-buckling analysis. Example 6.3 verifies the semi-rigid elastic post-buckling analysis. Example 6.4 verifies the plastic analysis of the bent frame which is governed by the tosional moment. Examples 6.5 and 6.6 verify the semi-rigid plastic collapse analysis.

\section{Example 6.1: Williams’ toggle frame}

Williams' toggle frame has been analyzed by many researchers to verify the numerical accuracy of their studies. Williams solved this frame using analytical and experimental tests. Papadrakakis [7] 
solved this problem by using the beam-column approach. Meek and Tan [47] used the so-called co-rotational finite element approach. Liew et al. [79] used the improved cubic element approach that accounts for some coupling effects. Wood and Zienkiewicz [35] employed a total Lagrangian finite element formulation in a continuous approach with five isoparametric elements per member.

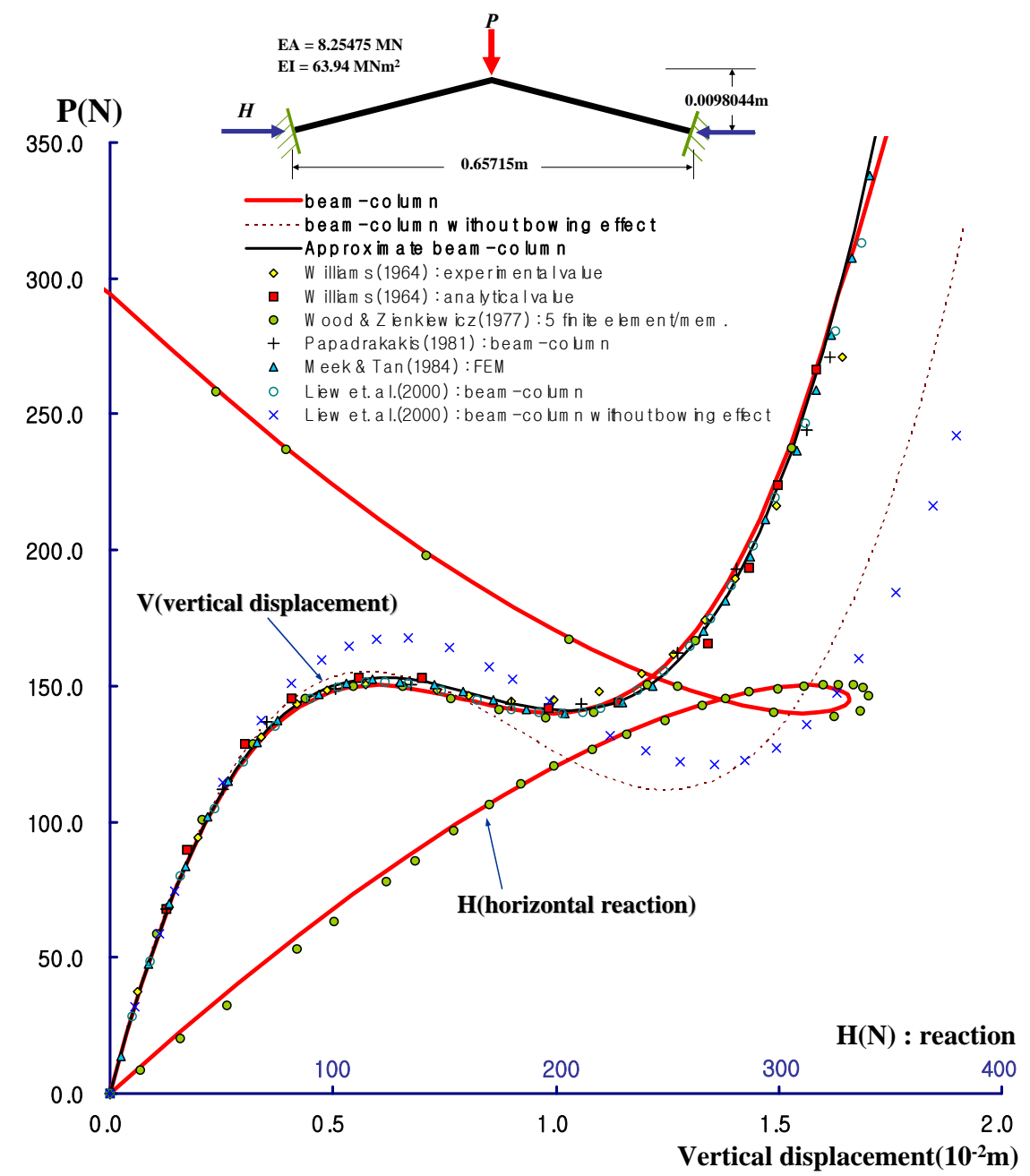

Figure 6. Williams' Toggle Frame: Geometry and Load-deflection Curves

The results of this problem, as obtained in this study, are illustrated in Figure 6 with one element per member as Papadrakakis [7], Meek and Tan [47] and Liew et al. [79]. The load-deflection curves are in good agreement with previous result curves. The load-deflection curve determined using the proposed beam-column element with a bowing effect is very close to the results predicted by Paradrakakis [7] and Liew et al. [79]. Our results without the bowing effect are similar to the results of Liew et al. [79] after the limit point of the post-buckling range, which did not consider the bowing effect. The load-deflection curve of the approximate beam-column approach is in good agreement with the curve of Meek and Tan [47].

\section{Example 6.2: 12-member hexagonal space frame}

The geometry and load-deflection curves for the 12-member frame dome are illustrated in Figure 7. The boundary conditions for this problem are roller and pin support. The results curves obtained using the proposed formulation, beam-column and approximate beam-column methods are plotted according to the boundary conditions. The resulting curves are in good agreement with previously published results $[7,47,48,58,79,80]$. 


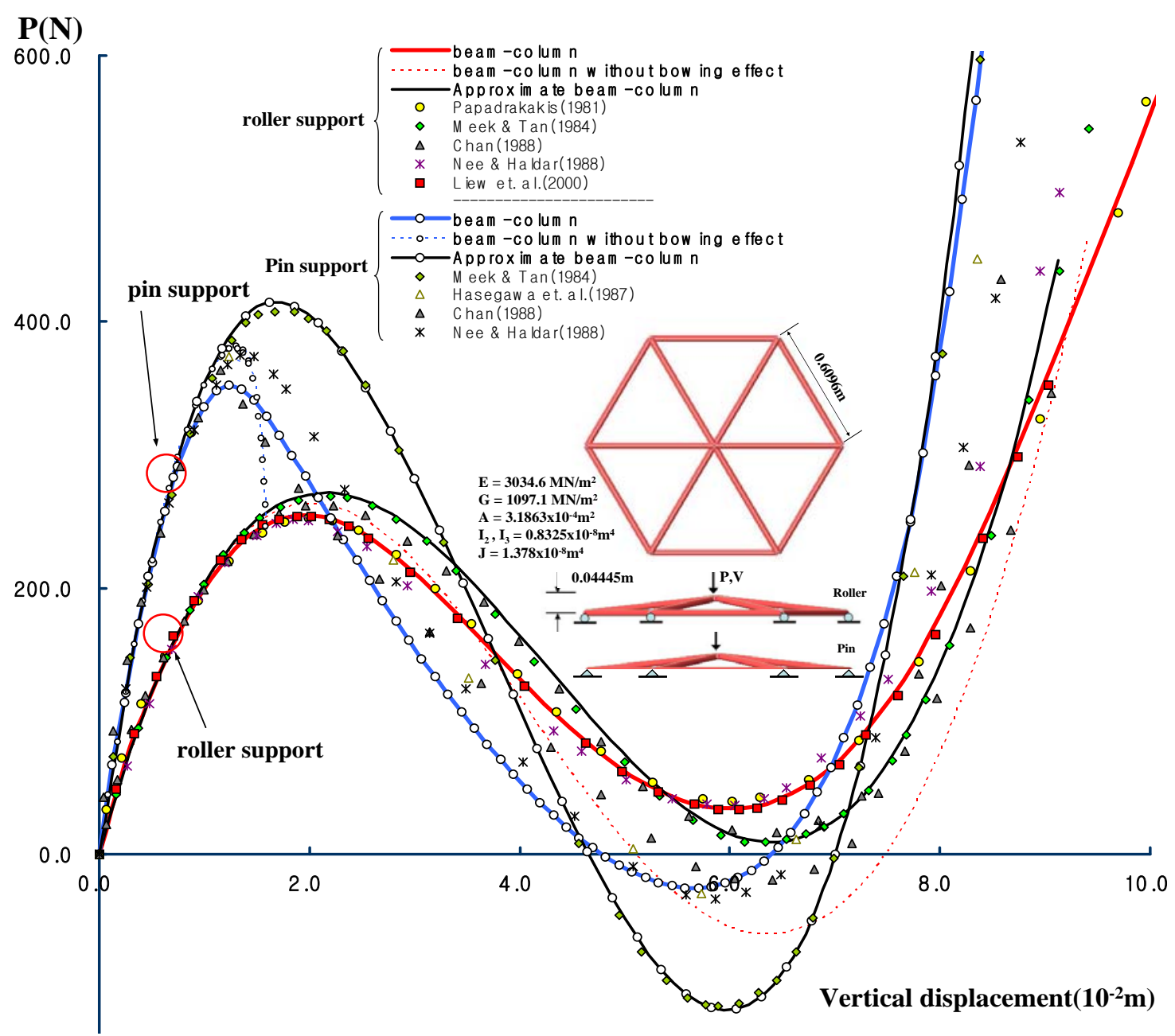

Figure 7. 12-member Frame Dome: Geometry and Load-deflection Curves

The load-deflection curve of the beam-column element is in accordance with Papadrakakis [7], Nee and Haldar [58] and Liew et al. [79] in the roller support condition and underestimates the load-deflection curves compared with the results of Hasegawa [80] and Nee and Haldar [58] in the pin-support condition. The load-deflection curves of the approximate beam-column element are in good agreement with Meek and Tan [47] for each boundary condition case. Chan [48] used two elements per member to analyze this problem using co-rotational cubic elements. Chan's load-deflection curves are plotted between the curves of the beam-column and approximate beam-column elements for the roller support condition. This implies the well-known fact that the beam-column element is more exact than the FE formulate element. Generally, a larger number of elements per member are needed to obtain an exact solution when a finite element formulation space frame is used.

\section{Example 6.3: 24-member hexagonal star-shaped shallow dome}

This model is known as the Stardome and is used as a verification example for nonlinear analysis of truss models. However, Meek and Tan [47] solved this problem as a rigid jointed space frame by keeping the member cross sectional area but decreasing the flexural stiffness in the vertical plane. The geometry and section properties are shown in Figure 8. Section type-1 and Section type-2 are rigid joints; Section type-3 is a pin joint. As shown in Figure 9, the load-deflection of the rigid jointed space frame converge to that of the pin-jointed truss load-deflection curve as the stiffness of section decreases. Finally, the structure was found to exhibit snap-through buckling. 
To verify the accuracy and applicability of the proposed semi-rigid connected beam-column element, the semi-rigid spring element, as described in Table 1, was introduced in both Section type-1 and Section type-2, and the structural flexibility was predicted with corresponding semi-rigid connection properties.

As shown in Figure 9, the resulting curves determined by the approximate beam-column element are in good agreement with the previous results of Meek and Tan [47]. It can be seen that the load-deflection path of the beam-column element gradually differs from that of the approximate beam-column in the large deformational post-buckling range of high axial force levels. These phenomenon result from the omission of the higher order terms in Eqs. 19-22 of approximate beam-column equation.

By decreasing the semi-rigidity of the connection, the structural behaviors tend to be more flexible and finally converge to a pin-jointed truss model, as shown in Figure 10 and Figure 11, which differ only in section properties.

Table 1. Semi-rigid Spring Rigidities for the 24-member Shallow Dome

\begin{tabular}{|c|c|c|c|}
\hline & $k_{x}$ & $k_{\theta 2}$ & $k_{\theta 3}$ \\
\hline Semi-rigid type-1 & $E A$ & $E I_{2} \times 0.5$ & $E I_{3} \times 0.5$ \\
\hline Semi-rigid type-2 & $E A$ & $E I_{2} \times 0.1$ & $E I_{3} \times 0.1$ \\
\hline Semi-rigid type-3 & $E A$ & $E I_{2} \times 0.02$ & $E I_{3} \times 0.02$ \\
\hline
\end{tabular}

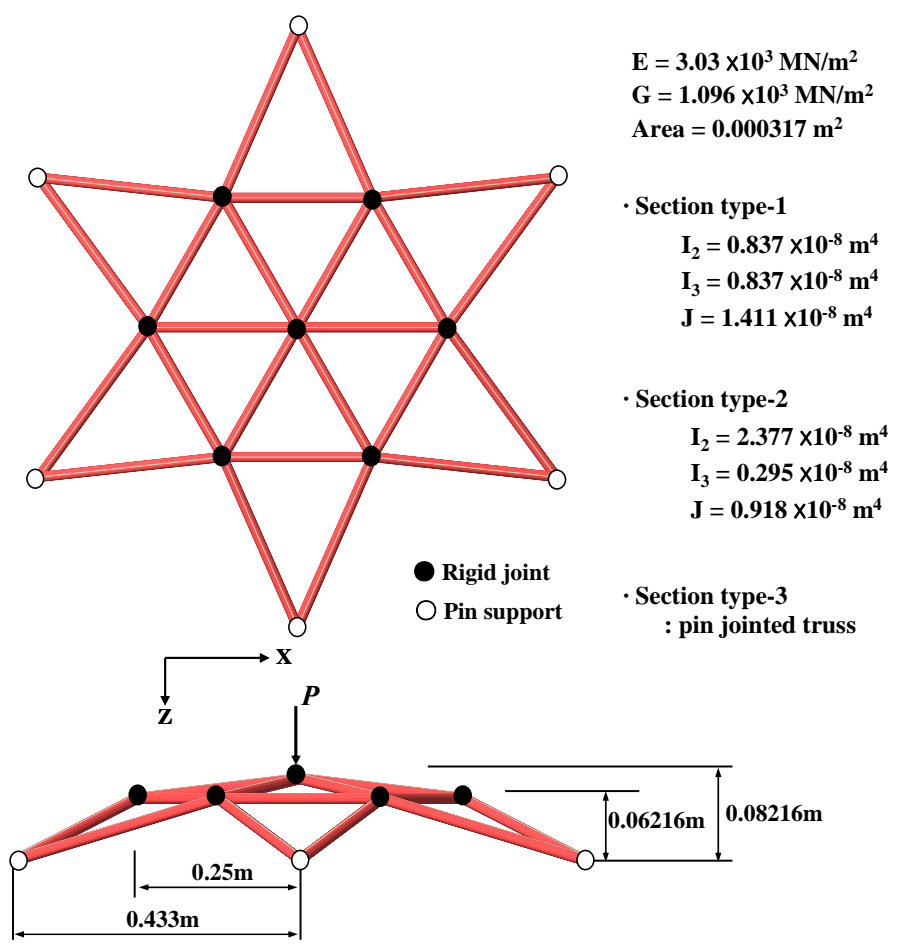

Figure 8. 24-member Shallow Dome: Geometry and Section Properties 


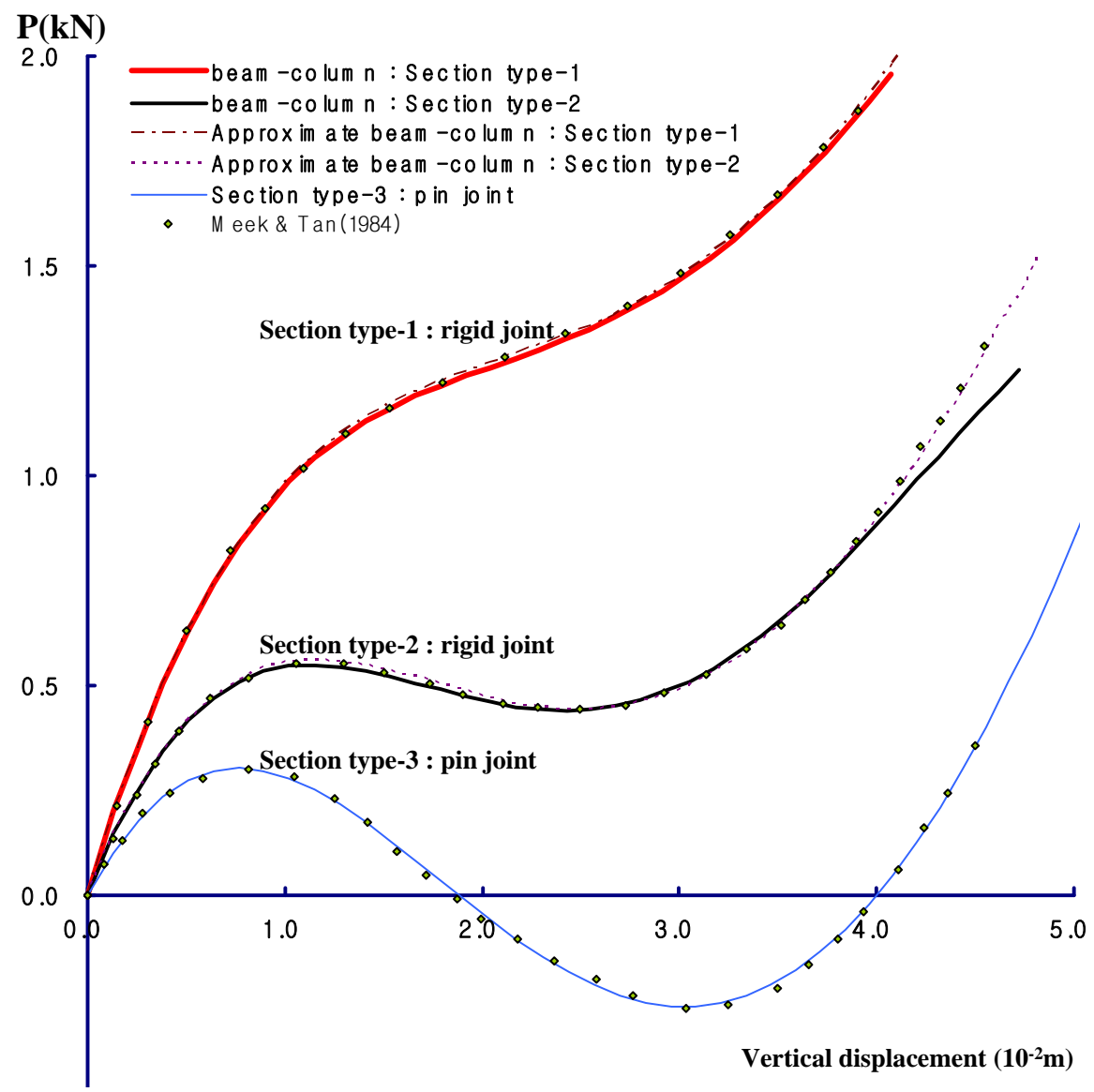

Figure 9. 24-member Shallow Dome: Load-deflection Curves for Each Section Types

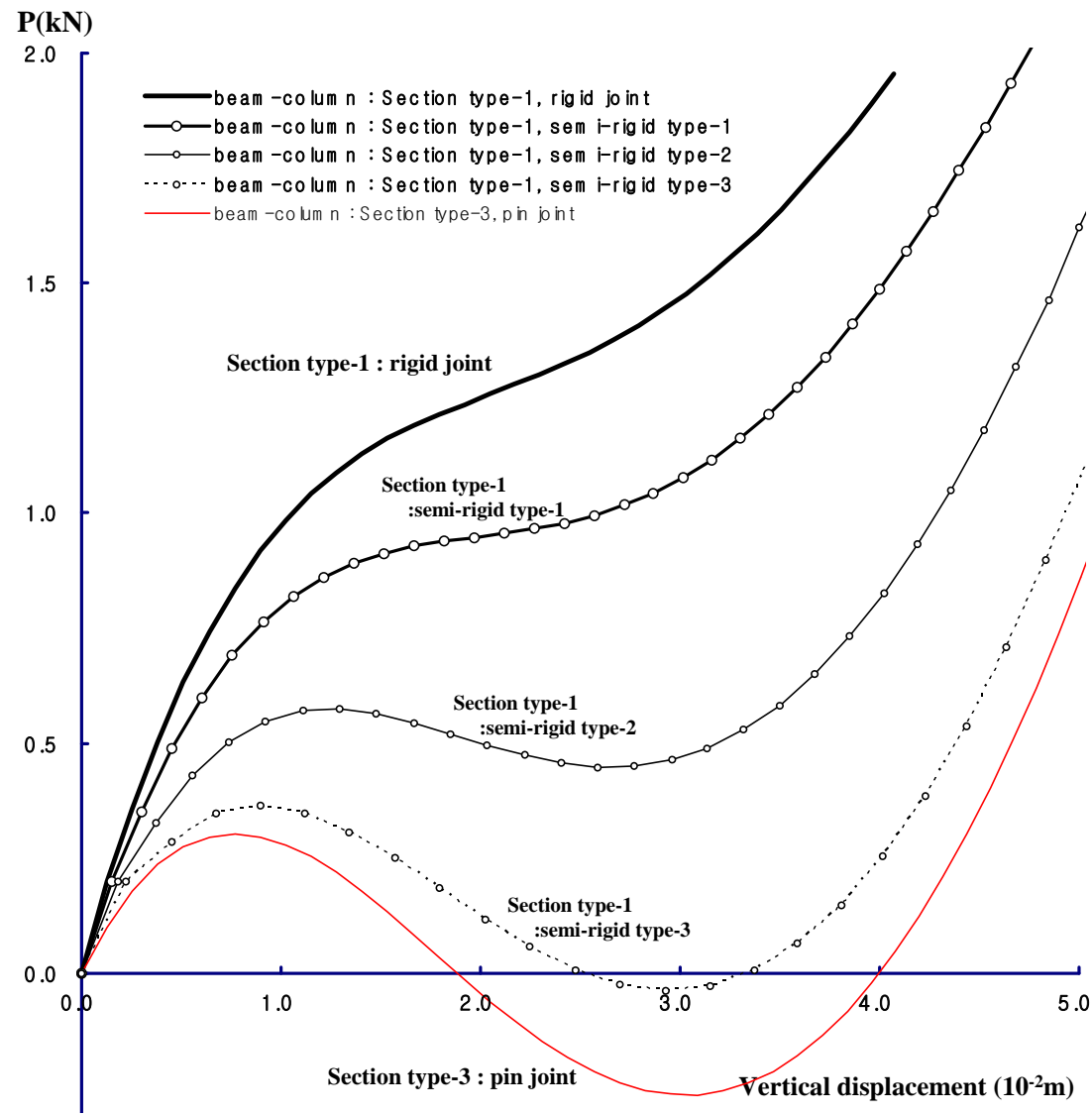

Figure 10. 24-member Shallow Dome: Load-deflection Curve for Semi-rigid Section Type-1 


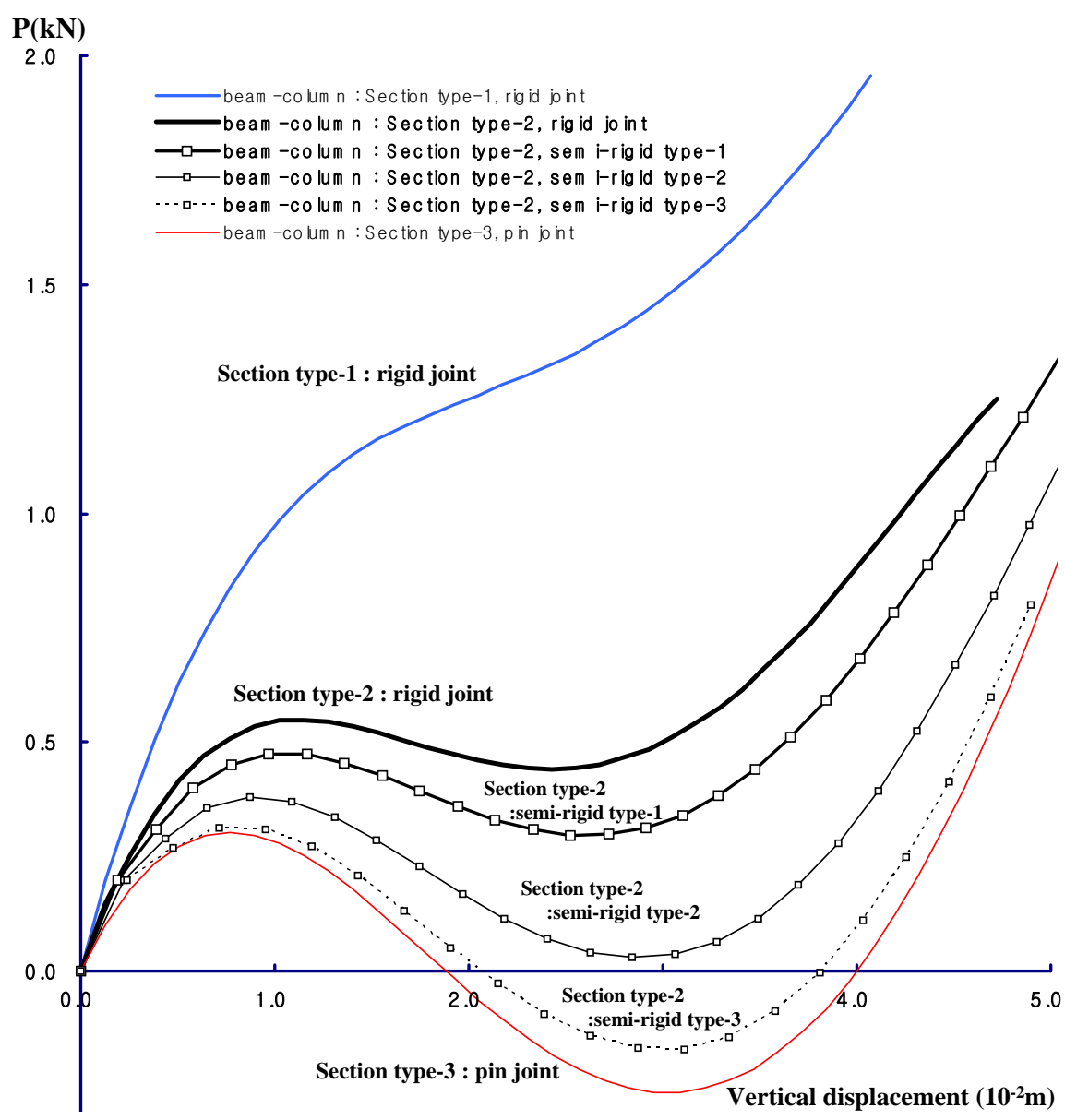

Figure 11. 24-member Shallow Dome: Load-deflection Curve for Semi-rigid Section Type-2

\section{Example 6.4: Horizontal bent frame}

The elasto-plastic analysis of a right-angle bent frame, as shown in Figure 12, was performed. The bent frame was subjected to a concentrated out-of-plane load in the vertical direction. A plastic hinge occurs at $\mathrm{A} \rightarrow \mathrm{D} \rightarrow \mathrm{B}$ nodes, sequentially. Shi and Atluri [57] used a yield function in which the interaction between the bending and torsional moments is considered, but the effect of axial force is neglected. Nee and Haldar [58] reported a load-deflection curve shape identical to that of Shi and Atluri [57] with a different yield function. Abbasnia and Kassimali [11] analyzed this problem with different cross section properties than those used by Nee and Haldar [58] and reported the behavior of large deformational rigid-body rotations.

To verify the response to the problem, two types of input models were considered for Nee and Haldar [58] and Abbasnia and Kassimali [11]; the elasto-plastic analysis was performed for the two models. Figures 12 and 13 illustrate the results of the load-deflection curves and deformed configurations. The results of the maximum load parameter (6.68) and the load-deflection curve obtained in this study are in good agreement with the results of Abbasnia and Kassimali [11], as shown in Figure 12. When the effects of plastic torsional deformation, given by Eq. 35, are not considered, a small deformation response may be obtained for a bent frame, and the load-deflection curves converge to those of Nee and Haldar [58] and Shi and Atluri [57], as shown in Figure 13. 


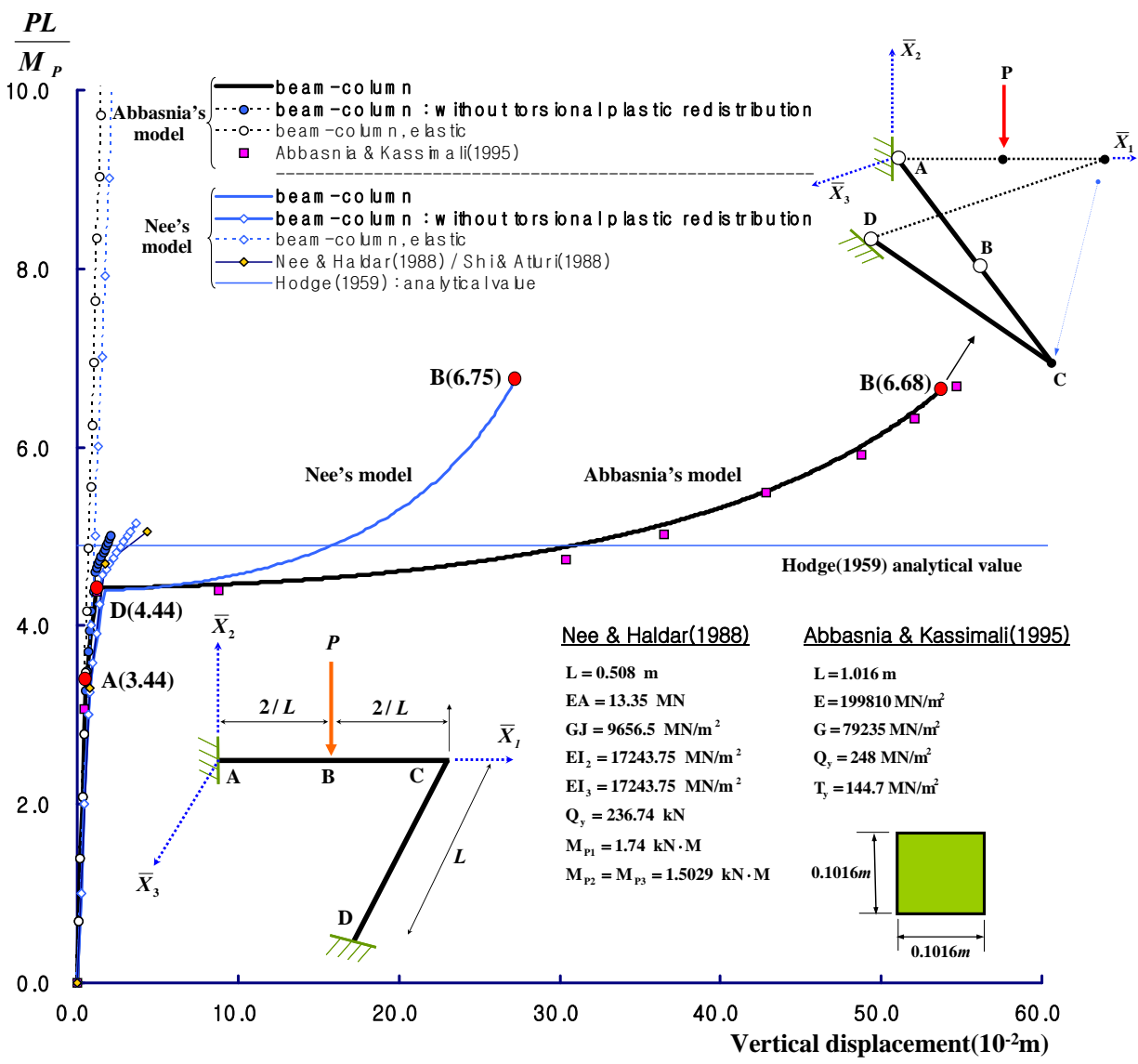

Figure 12. Horizontal Bent Frame: Geometry and Load-deflection Curve

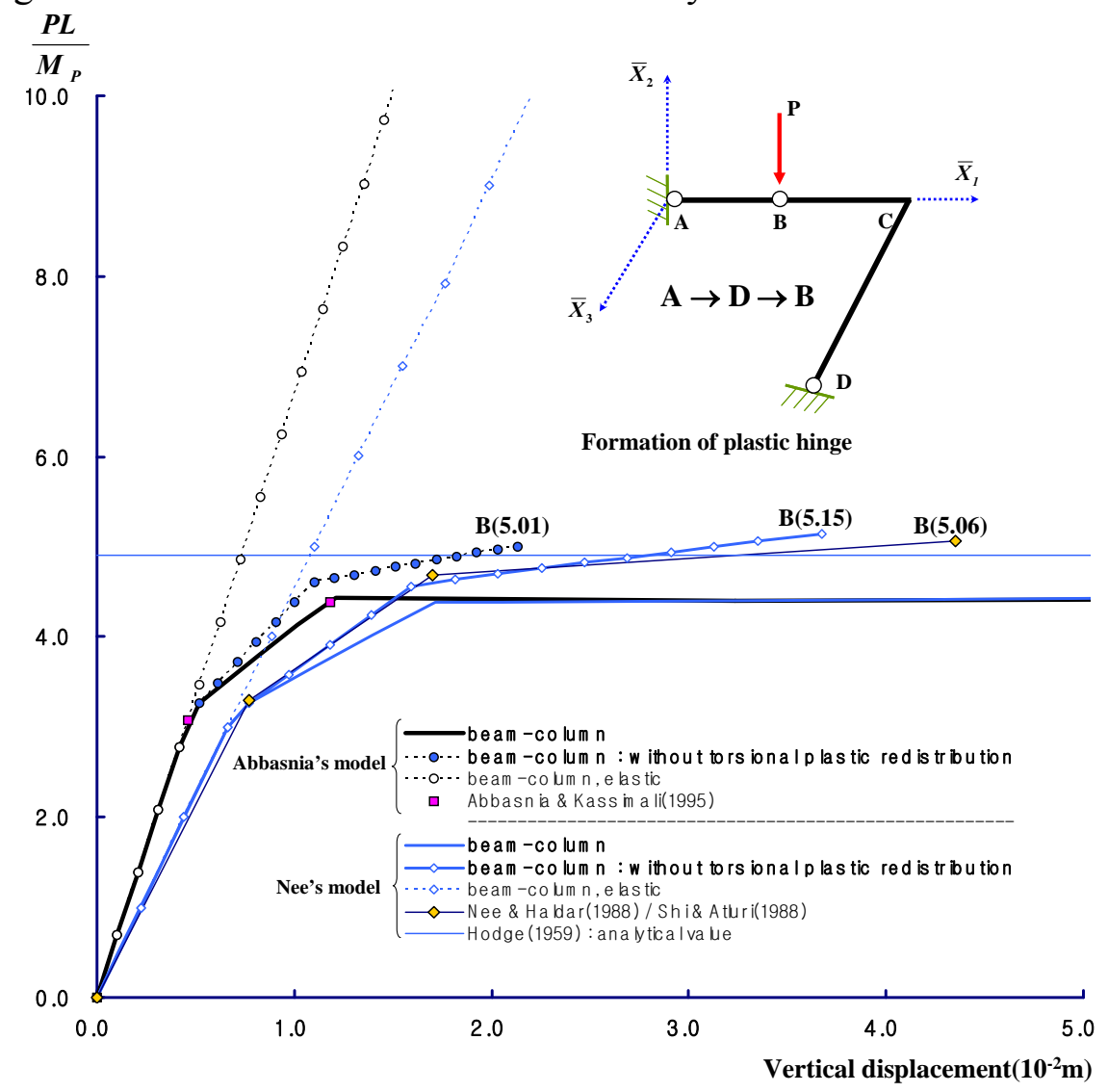

Figure 13. Horizontal Bent Frame: Detailed Load-deflection Curve 
As noted by Abbasnia and Kassimali [11], after a plastic hinge develops at nodes A and D, the structure becomes geometrically unstable and undergoes large rigid-body rotations to develop resistance to the applied load until a plastic hinge develops at node $\mathrm{B}$.

The results of the maximum load parameter (6.68) and the load-deflection curve obtained in this study are in good agreement with the results of Abbasnia and Kassimali [11], as shown in Figure 12. When the effects of plastic torsional deformation, given by Eq. 35, are not considered, a small deformation response may be obtained for a bent frame, and the load-deflection curves converge to those of Nee and Haldar [58] and Shi and Atluri [57], as shown in Figure 13. As noted by Abbasnia and Kassimali [11], after a plastic hinge develops at nodes $\mathrm{A}$ and $\mathrm{D}$, the structure becomes geometrically unstable and undergoes large rigid-body rotations to develop resistance to the applied load until a plastic hinge develops at node B.

Hodge [81] reported the corresponding value of the load parameter to be 4.9. Ueda and Yao [82] showed that the load parameter obtained by Hodge was the lower bound. Thus, the result of this example may be understood as acceptable and reasonable for elasto-plastic analysis.

\section{Example 6.5: 18-member frame dome}

This verification example is an 18-member frame dome used to analyze the semi-rigid elasto-plastic large deformational response, as shown in Figures 14 and 15. The overall comparative load-deflection curves that are plotted in these figures show good agreement with previously reported results. Paradrakakis [83] used a finite element-formulated 48-member system for this problem. However, many other researchers $[11,34,56,57]$ used one element per member, as in this study.

The results obtained using the proposed beam-column element show good agreement with the results of Kassimali and Abbasnia [8] until the buckling range is reached; our load-deflection curve proceeded until the large deformational post-buckling range, as shown in Figure 14. The elastic analysis capacity of the proposed elements has acceptable merit and applicability. Moreover, the elasto-plastic response of this problem shows good agreement with the results of Agyris et al. [34] and Abbasnia and Kassimali [11] until the plastic limit point. Conversely, in this study, after this limit point, the analysis procedure and structural response continued until plastic hinges occurred at node 3 with elasto-plastic large deformational behaviors.

The bowing effect of the proposed beam-column element influences the comprehensive effect for the elastic response governed by the geometric nonlinearity but not for the plastic case. The load-deflection curves are closely plotted for the low axial-force level, plastic analysis case, as shown in Figure 14. Therefore, for the plastic analysis case, it is not necessary to consider the bowing effect. Such a phenomenon also occurred in Example 6.6 (below). The collapse mechanism for this example goes sequentially to nodes (1) $\rightarrow(2) \rightarrow(3)$; the load levels and the points at which the plastic hinges occurred are marked in the figure. 


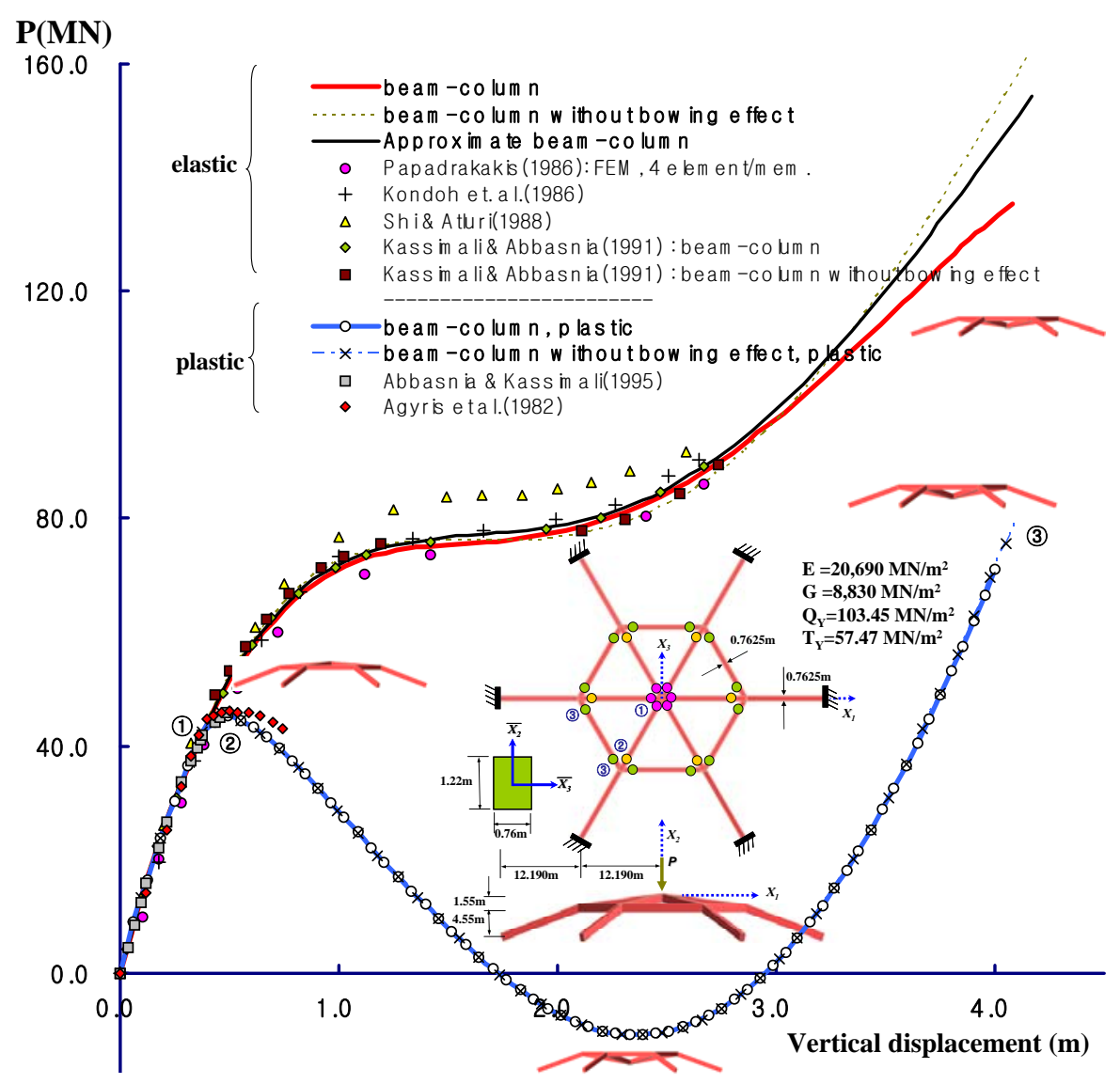

Figure 14. 18-member Frame Dome: Geometry and Load-deflection Curve

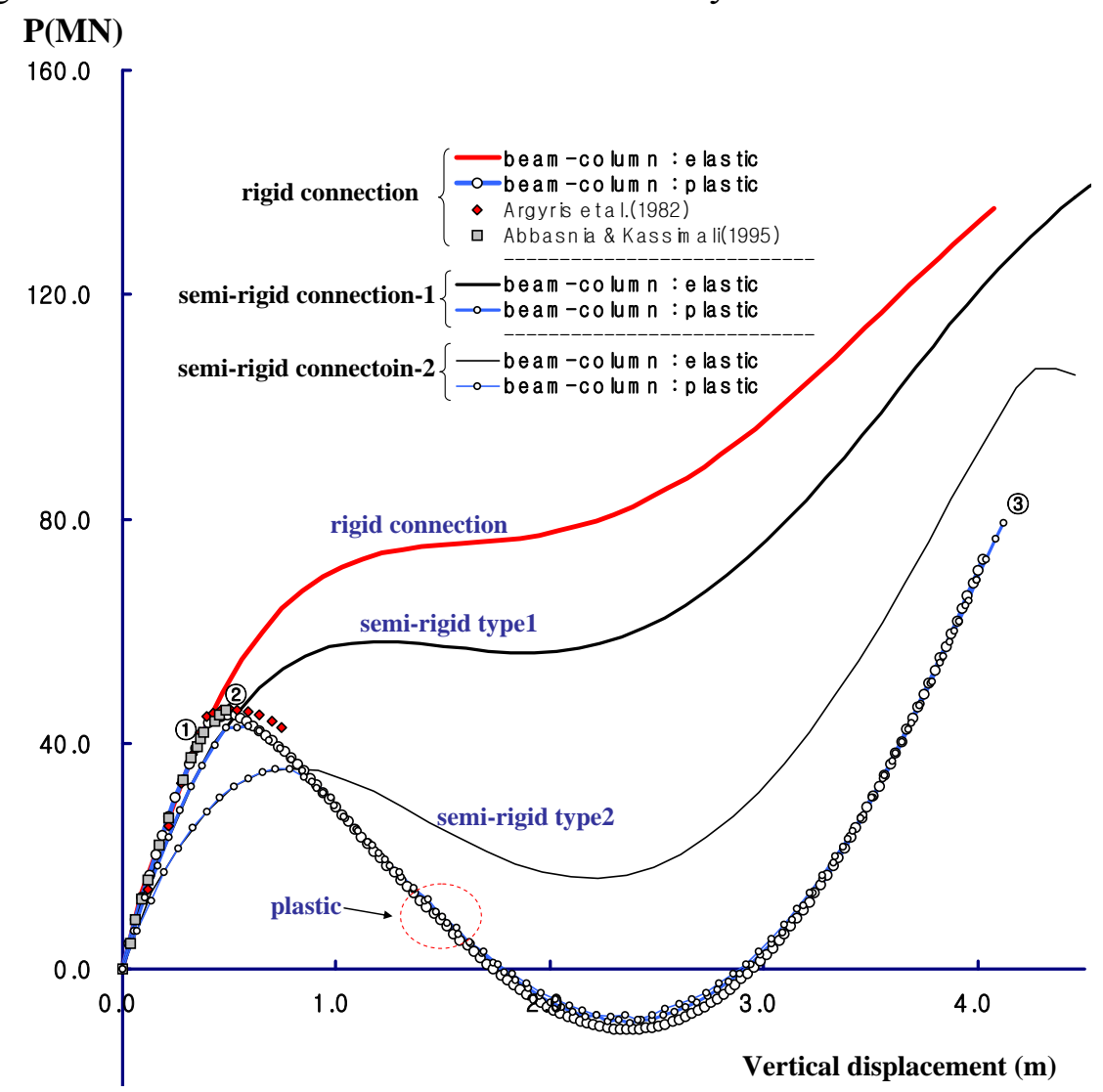

Figure 15. 18-member Frame Dome: Semi-rigid Elasto-plastic Response 
Table 2. Semi-rigid Spring Rigidities for the 18-member Frame Dome

\begin{tabular}{|l|c|c|c|}
\hline & $k_{x}$ & $k_{\theta 2}$ & $k_{\theta 3}$ \\
\hline Semi-rigid type-1 & $E A$ & $E I_{2} \times 0.3$ & $E I_{3} \times 0.3$ \\
\hline Semi-rigid type-2 & $E A$ & $E I_{2} \times 0.05$ & $E I_{3} \times 0.05$ \\
\hline
\end{tabular}

Figure 15 shows the semi-rigid elasto-plastic response of this example. The elastic semi-rigid spring rigidities are described in Table 2. From the analyzed response, it can be seen that the elastic and plastic limit load levels are influenced by the applied semi-rigidities. The plastic hinges of perfect plastic material model without strain-hardening of joint (1) and (2) make the structure as ideally pin jointed dome structures. Therefore, the load-deflection paths after plastic limit load trace similar curves. The elastic semi-rigid joint flexibility influences the response of elastic load-deflection curves but not plastic case.

\section{Example 6.6: two-story frame}

A two-story frame, as shown in Figure 16, was verified for the semi-rigid elasto-plastic analysis. Plastic zone and plastic hinge approaches were used by Argyris et al. [34] and Abbasnia and Kassimali [11] respectively. The load-deflection curves at node (a) in Figure 16 are illustrated in Figure 17. As a result, the response curve shows good agreement with results of previous work by Argyris et al. [34] and Abbasnia and Kassimali [11]. The bowing effect slightly influences the plastic response in this example, as also seen in Example 6.5 for the plastic case. The sequence of the plastic hinge formation or collapse mechanism is from (1) $\rightarrow(2) \rightarrow(3) \rightarrow(4) \rightarrow(5)$ nodes of Figure 16. Figure 18 shows the deformed shape of structures according to the analysis results.

The four-parameter Ramberg-Osgood hysteresis model of Hart and Wilson [84] was adopted in this example for the $y$ - and z-axis rotational terms. The initial stiffness of the semi-rigid springs are illustrated in Table 3, and the relative spring yielding values for each axis are assumed as the value of the connected member. According to the semi-rigid flexibility of connections with Ramberg-Osgood control parameters $\alpha$ and $\gamma$, the load-deflection curves are plotted in Figure 17.

Table 3. Semi-rigid Spring Rigidities for a Two-story Frame

\begin{tabular}{|c|c|c|c|}
\hline & $k_{x}$ & $k_{\theta 2}$ & $k_{\theta 3}$ \\
\hline Semi-rigid & $E A$ & $E I_{2} \times 0.04$ & $E I_{3} \times 0.04$ \\
\hline
\end{tabular}

\section{CONCLUSION}

The elasto-plastic post-buckling analysis of a semi-rigid space frame is presented. The Eulerian finite deformation formulations were included for large deformations and small strains. The formulation to represent the space frame was a conventional beam-column element with a bowing effect. The lateral-torsional effect was included in asymmetric rotational tangent stiffness. However, the shear, axial-torsional and warping effects were not considered for the sake of simplicity. The joint connection characteristics were represented by semi-rigid spring elements. The well-known static condensation processes were adopted for the element stiffness and equilibrium equations. Highly nonlinear load-deflection curves were traced by the arc-length method with an asymmetric tangent stiffness matrix. 


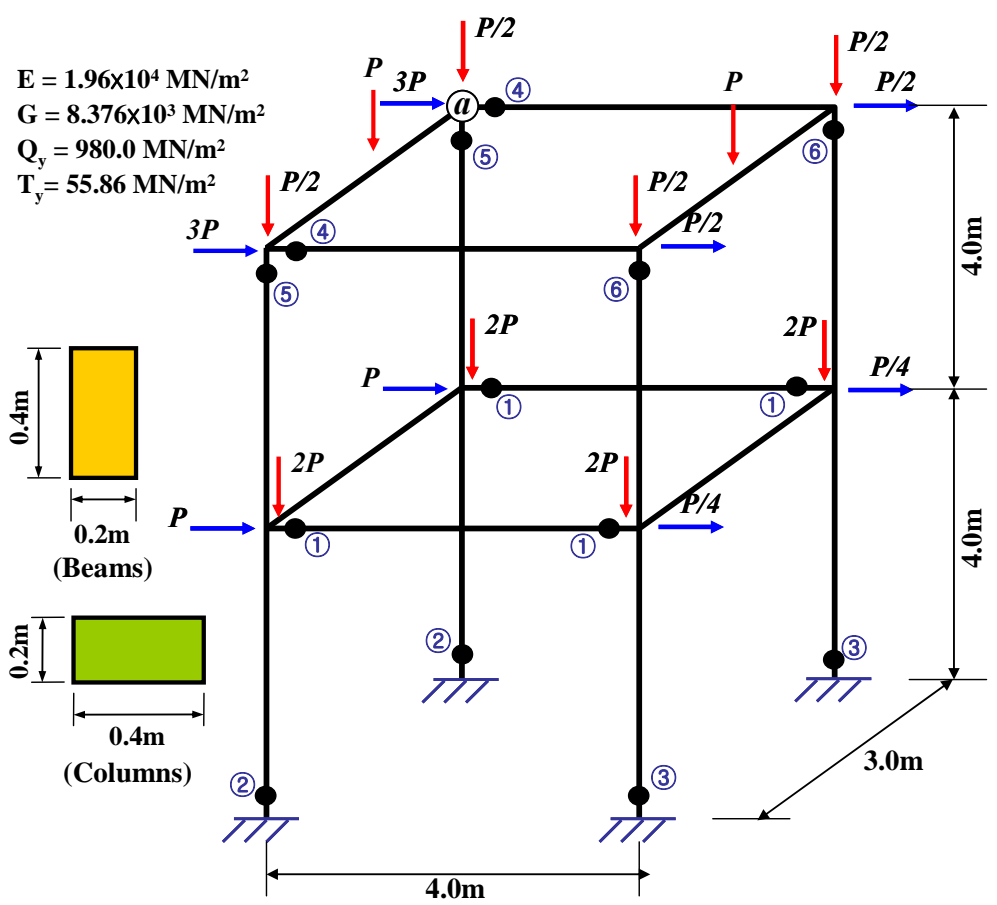

Figure 16. Two-story frame: geometry and properties

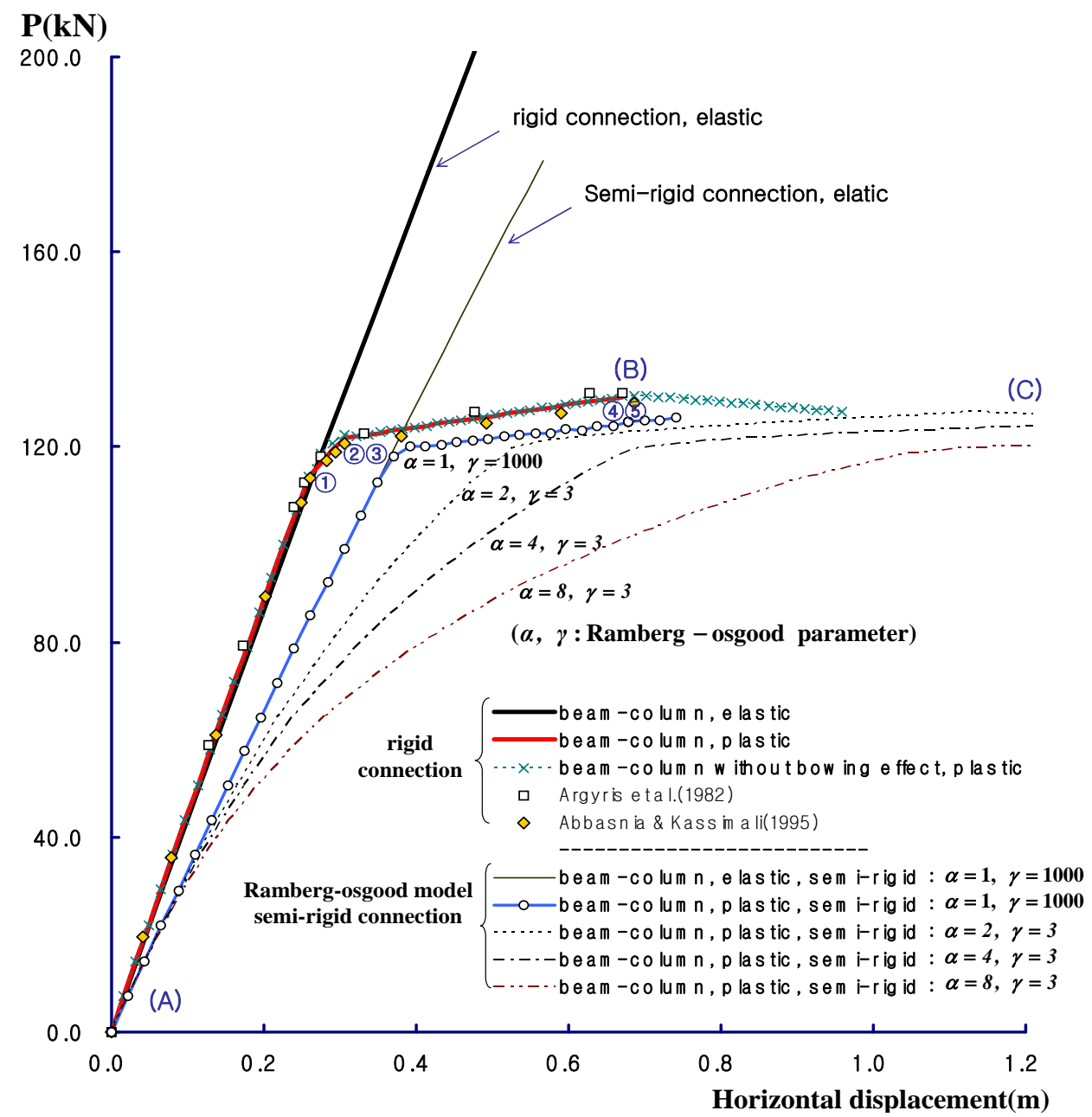

Figure 17. Two-story Frame: Load-deflection Curves 


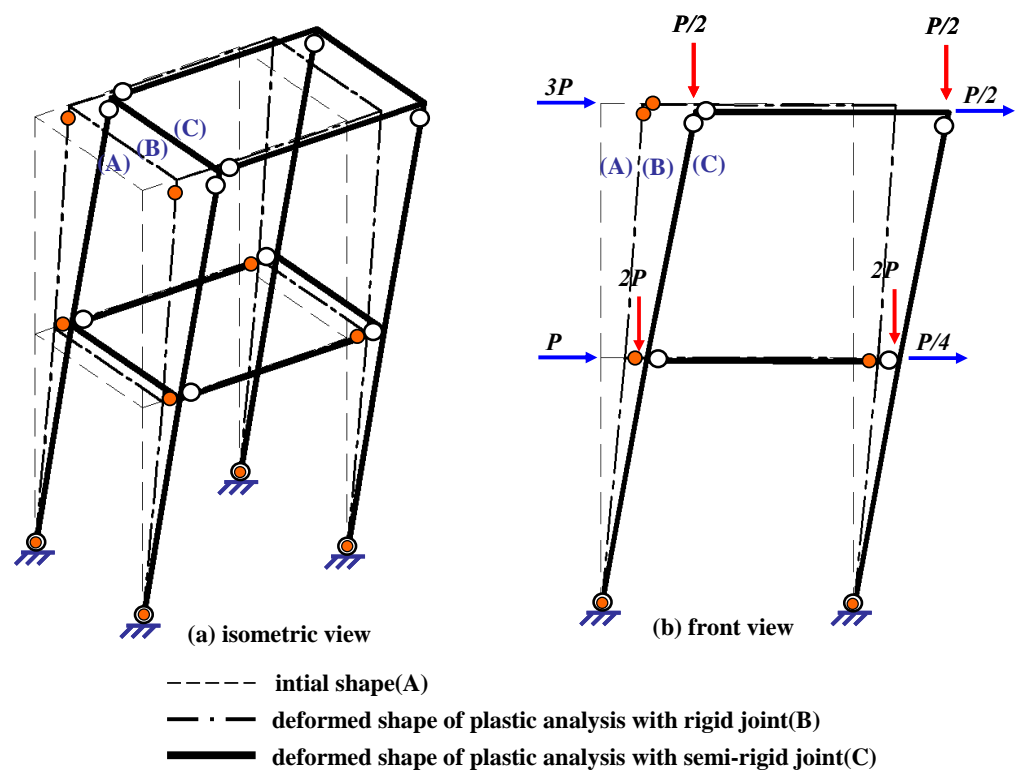

Figure 18. Two-story Frame: Deformed Shape

The proposed simple and effective space frame element with a semi-rigid connection is the result of well-defined and previously reported research. The theories were combined for the purposes of numerical capacity and applicability. The results of the verified examples show good agreement with results in the literature. Moreover, in some cases, newly reported result curves and values are obtained. It was observed that the proposed method is reliable and accurate for studying the post-buckling behavior of finite deformed space frames and is applicable to various nonlinear problems.

\section{ACKNOWLEDGEMENTS}

This research was supported by a grant (code\#'09 R\&D A01) from Cutting-edge Urban Development Program funded by the Ministry of Land, Transport and Maritime Affairs of Korean government.

\section{REFERENCES}

[1] Renton, J.D., "Stability of Space Frames by Computer Analysis", J. Sruct. Div., ASCE, 1962, Vol. 88, No. 8, pp. 81-103.

[2] Saafan, S.A., "Nonlinear Behavior of Structural Plane Frames", J. Sruct. Div., ASCE, 1962, Vol. 89, No. 4, pp. 557-579.

[3] Oran, C., "Tangent Stiffness in Space Frame”, J. Struc. Div., ASCE, 1973, Vol. 99, No. 6, pp. 987-1001.

[4] Chen, W.F. and Lui, E.M., "Stability Design of Steel Frames", CRC Press, 1991.

[5] Chen, W.F., Goto, Y. and Liew, J.Y.R., "Stability Design of Semi-Rigid Frames", John Willey \& Sons, Inc, 1996.

[6] Chen, W.F. and Kim, S.E., "LRFD Steel Design using Advanced Analysis", CRC Press Boca Raton (FL), 1997.

[7] Papadrakakis, M., "Post Buckling Analysis of Spatial Structures by Vector Iteration Methods", Computers \& Structures, 1981, Vol. 14, pp. 393-402. 
[8] Kassimali, A. and Abbasnia, R., "Large Deformation Analysis of Elastic Space Frames", J. Struct. Eng., ASCE, 1991, Vol. 117, No. 7, pp. 2067-2087.

[9] Kassimali, A., "Large Deflection Analysis of Elastic-plastic Frames", J. Struct. Eng., ASCE, 1983, Vol. 109, No. 8, pp. 1869-1886.

[10] Chandra, R., Krishna, P. and Trikha, D.N., "Elastic-plastic Analysis of Steel Space Structures”, J. Struct. Engng, ASCE, 1990, Vol. 26, No. 3, pp. 939-955.

[11] Abbasnia, R. and Kassimali, A., "Large Deformation Elastic-plastic Analysis of Space Frames", J. Construct. Steel Research, 1995, Vol. 35, pp. 275-290.

[12] Spillers, W.R., "Geometric Stiffness Matrix for Space Frames", Computers \& Structures, 1990, Vol. 36, No. 1, pp. 29-37.

[13] Spillers, W.R. and Shams, M.H., "Three-Dimensional Beam-Columns", Computers \& Structures, 1994, Vol. 52, No. 3, pp. 449-460.

[14] Spillers, W.R. and Rashidi, S., "Member Stiffness for Three-Dimensional Beam-Columns", J. Struct. Eng., ASCE, 1997, Vol. 127, No. 7, pp. 971-972.

[15] Levy, R. and Spillers, W.R., "Analysis of Geometrically Nonlinear Structures, 2nd ed.", Kluwer Academic Publishers, 2003.

[16] Kim, S.E., Kim, Y. and Choi, S.H., "Nonlinear Analysis of 3-D Steel Frames", Thin Walled Struct, 2001, Vol. 39, pp.445-461.

[17] Kim, S.E. and Choi, S.H., "Practical Advanced Analysis for Semi-rigid Space Frames", Internat. J. Solids Structures, 2001, Vol. 38, No.50-51, pp. 9111-9131.

[17] Kim, S.E., Park, M.H. and Choi, S.H., "Direct Design of Three-dimensional Frames using Practical Advanced Analysis", Engineering Structures, 2001, Vol. 23, No. 11, pp. 1491-1502.

[18] Gallagher, R.H. and Padlog, J., "Discrete Element Approach to Structural Instability Analysis", AAIA J., 1963, Vol. 1, 1437-1439.

[19] Przemieniecki, J.S., "Theory of Matrix Structural Analysis", New York, McGraw-Hill, 1968.

[20] Jennings, A., "Frame Analysis including Change in Geometry", J. Struct. Div, ASCE, 1968, Vol. 94, pp. 627-44.

[21] Porter, F.L. and Powell, G.H., "Static and Dynamic Analysis of Inelastic Framed Structures", Report No. EERC 71-3. Earthquake Engineering Research Centre, University of California at Berkeley, CA, 1971.

[22] Chen, P.F. and Powell, G.H., "Generalized Plastic Hinge Concepts for 3D Beam-column Elements", Report No. EERC 82-20. Earthquake Engineering Research Centre, University of California at Berkeley, CA, 1982.

[23] Powell, G.H. and Chen, P.F., "3-D Beam-column Element with Generalized Plastic Hinges", J. Engng. Mech. ASCE, 1986, Vol. 112, No. 7, pp. 627-641.

[24] Gattass, M. and Abel, J.F., "Equilibrium Considerations of the Updated Lagrangian Formulation of Beam-columns with Natural Concepts", Int. J. Numer. Meth. Engng., 1987, Vol. 24, pp. 2119-2141.

[25] Makowski, Z.S., "Regular Lattice Plates and Shells", Elsevier, 1990.

[26] White, D.W. and Hajjar, J., "Application of Second-order Elastic Analysis in LRFD: Research to Practice”, Engng. J, AISC, 1991, Vol. 28, pp. 133-148.

[27] Yang, Y.B. and Leu, L.J., "Non-linear Stiffnesses in Analysis of Planar Frames", Comput. Methods Appl. Mech. Engrg. 1994, Vol. 117, pp. 233-247.

[28] Yang, Y.B. and Kuo, S.R., "Theory \& Analysis of Nonlinear Frames", Prentice-Hall, 1994.

[29] McGuire, W., Gallagher, R.H. and Ziemian, R., "Matrix Structural Analysis, 2nd Ed." New York, John Wiley and Sons, 2000. 
[30] Argyris, J., “An excursion into Large Rotations”, Comput. Methods Appl. Mech. Engrg., 1982, Vol. 32, pp. 85-155.

[31] Argyris, J.H., Dunne, P.C. and Scharpf, D.W., "On Large Displacement Small Strain Analysis of Structures with Rotational Degrees of Freedom", Comput. Methods Appl. Mech. Engrg., 1978, Vol. 14, pp. 401-451.

[32] Argyris, J.H., Balmer, H., Doltsinis, I.S.T., Dunne, P.C., Haase, M., Kleiber, M., Malejannakis G.A., Mlejnek, H.P., Muller, M. and Scharpf, D.W., "Finite Element Method-The Natural Approach", Comput. Methods Appl. Mech. Engrg., 1979, Vol. 17/18, pp. 1-106.

[33] Argyris, J.H., Hilpert, O., Malejannakis, G.A. and Scharpf, D.W., "On the Geometrical Stiffness of a Beam in Space-A Consistent v.w. approach", Comput. Methods Appl. Mech. Engrg., 1979, Vol. 20, pp. 105-131.

[34] Argyris, J.H., Boni, B., Hindenlang, U. and Kleiber, M., "Finite Element Analysis of Two and Three Dimensional Elasto-plasic Frames-The Natural Approach", Comput. Methods Appl. Mech. Engrg., 1982, Vol. 35, pp. 221-248.

[35] Wood, R.D. and Zienkiewicz, O.C., "Geometrically Non-linear Finite Element Analysis of Beam, Frames, Arches and Axisymmetric Shells”, Computers \& Structures, 1977, Vol. 7, pp. 725-735.

[36] Bathe, K.J. and Bolourchi, S., "Large Displacement Analysis of Three-dimensional Beam Structures", Int. J. Num. Meth. Eng., 1979, Vol. 14, pp. 961-986.

[37] Reissner, E., "On Finite Deformation of Space-curved Beams”, J. Appl. Math. Phys., 1981, Vol. 32, pp. 734-744.

[38] Simo, J.C., "A Finite Strain Beam Formulation, Part I, The Three-dimensional Dynamic Problem", Comput. Methods Appl. Mech. Engrg., 1985, Vol. 49, pp. 55-70.

[39] Simo, J.C. and Vu-Quoc, L., "A Three-dimensional Finite-strain Rod Model, Part II, Computational Aspects”, Comput. Methods Appl. Mech. Engrg., 1986, Vol. 58, pp. 79-116.

[40] Simo, J.C. and Vu-Quoc, L., "On the Dynamics in Space of Rods Undergoing Large Motions-A Geometrically Exact Approach”, Comput. Methods Appl. Mech. Engrg., 1988, Vol. 66, pp. 125-161.

[41] Simo, J.C. and Vu-Quoc, L., "A Geometrically Exact Rod Model Incorporating Shear and Torsion-warping Deformation”, Int. J. Solids Struct., 1991, Vol. 27, pp. 371-393.

[42] Simo, J.C., "The (Symmetric) Hessian for Geometrically Nonlinear Models in Solid Mechanics: Intrinsic Definition and Geometric Interpretation”, Comput. Methods Appl. Mech. Engrg., 1992, Vol. 96, pp. 189-200.

[43] Cardona, A. and Geradin, M., "A Beam Finite Element Non-linear Theory with Finite Rotations", International Journal for Numerical Methods in Engineering, 1988, Vol. 26, pp. 2403-2438.

[44] Ibrahimbegovic, A., "Computational Aspects of Vector-like Parametrization of three-dimensional finite rotations", Int. J. Num. Meth. Eng., 1995, Vol. 38, pp. 3653-3673.

[45] Zupan, D. and Saje, M., "Finite-element Formulation of Geometrically Exact Three-dimensional Beam Theories based on Interpolation of Strain Measures", Comput. Methods Appl. Mech. Engrg., 2003, Vol. 192, pp. 5209-5248.

[46] Mata, P., Oller, S. and Barbat, A.H., "Static Analysis of Beam Structures under Nonlinear Geometric and Constitutive Behavior", Comput. Methods Appl. Mech. Engrg., 2007, Vol. 196, pp. 4458-4478.

[47] Meek, J.L. and Tan, H.S., "Geometrically Nonlinear Analysis of Space Frames by an Incremental Iterative Technique”, Comput. Methods Appl. Mech. Engrg., 1984, Vol. 47, pp. 261-282. 
[48] Chan, S.L., "Geometric and Material Nonlinear Analysis of Beam-Columns and Frames Using the Minimum Residual Displacement Method”, Int. J. Num. Meth. Eng., 1988, Vol. 26, No. 12, pp. 2657-2669.

[49] Crisfield, M.A. and Cole, G., "Co-rotational Beam Elements for Two and Three-dimensional Nonlinear Analysis, Discretisation Methods in Structural Mechnics”, Ed. Kuhn, G. and Mang, H., Spring-Verlag, 1989, pp. 115-124.

[50] Crisfield, M.A., "A Consistent Co-rotational Formulation for Nonlinear Three Dimensional Beam Elements”, Comput. Methods Appl. Mech. Engrg., 1990, Vol. 81, pp. 131-150.

[51] Nour-Omid, B. and Rankin, C.C., "Finite Rotation Analysis and Consistent Linearization using Projectors", Comput. Methods Appl. Mech. Eng., 1991, Vol. 93, pp. 353-384.

[52] Teh, L.H. and Clarke, M.J., "Co-rotational and Lagrangian Formulations of Elastic Three-dimensional Beam Finite Elements”, J. Construct. Steel Research, 1998, Vol. 48, pp. $23-44$.

[53] Battini, J.M. and Pacoste, C., "Co-rotational Beam Elements with Warping Effects in Instability Problems", Comput. Methods Appl. Mech. Engrg., 2002, Vol. 191, pp. $1755-1789$.

[54] Battini, J.M. and Pacoste, C., "Plastic Instability of Beam Structures using Co-rotational Elements", Comput. Methods Appl. Mech. Engrg., 2002, Vol. 191, pp. 5811-5831.

[55] Izzuddin, B.A. and Elnashai, A.S., "Eulerian Formulation for Large Displacement Analysis of Space Frames”, J. Eng. Mech., ASCE, 1993, Vol. 119, No. 3, pp. 549-569.

[56] Kondoh, K. and Atluri, S.N., "Simplified Finite Element Method for Large Deformation, Post-Buckling Analysis of Large Frame Structures, Using Explicurly Derived Tangent Stiffness Matrices", Int. J. Num. Meth. Eng., 1986, Vol. 3, No. 1, pp. 69-90.

[57] Shi, G. and Atluri, S.N., "Elasto-plastic Large Deformation Analysis of Space-frames : A Plastic-hinge and Stress-based Explicit Derivation of Tangent Stiffness", Int. J. Num. Meth. Eng., 1988, Vol. 26, pp. 589-615.

[58] Nee, K.M. and Haldar, A., "Elastoplastic Nonlinear Post-Buckling Analysis of Partially Restrained Space Structures", Comput. Methods Appl. Mech. Engrg., 1988, Vol. 71, pp. 69-97.

[59] Downer, J.D., Park, K.C. and Chiou, J.C., 'Dynamics of Flexible Beams for Multibody Systems: A Computational Procedure', Comput. Methods Appl. Mech. Engrg., 1992, Vol. 96, pp. 373-408.

[60] Park, M.S. and Lee, B.C., "Geometrically Non-linear and Elastoplastic Threedimensional Shear Flexible Beam Element of Von-Mises-type Hardening Material", Int. J. Numer. Methods Engrg., 1996, Vol. 39, pp. 383-408.

[61] Clarke, M.J. and Hancock, G.J., "Finite Element Nonlinear Analysis of Stressed-arch Frames", J. Struct. Engng., ASCE, 1991, Vol. 117, No.28, pp. 19-37.

[62] Attalla, M.R., Deierlein, G.G. and McGuire, W., "Spread of Plasticity: Quasi-plastic Hinge Approach", J. Struct. Eng., ASCE, 1994, Vol. 120, No. 8, pp. 2451-2473.

[63] Clarke, M.J. and Hancock, G.J., "A Study of Incremental-Iterative Strategies for Nonlinear Analysis”, Int. J. Numer. Methods Engrg., 1990, Vol. 29, pp. 1365-1391.

[64] The, L.H. and Clarke, M.J., "Plastic-zone Analysis of 3D Steel Frames using Beam Elements", J. Struct. Engng. 1999, Vol. 125, pp. 1328-1337.

[65] Gruttmann, R., Sauer, R. and Wagner, W., "Theory and Numerics of Three-dimensional Beams with Elastoplastic Behaviour", Int. J. Numer. Meth. Engrg., 2000, Vol. 48, pp. $1675-1702$.

[66] Jiang, X.M., Chen, H. and Liew, J.Y.R., "Spread-of-plasticity Analysis of Three-dimensional Steel Frames", J. Construct. Steel Research, 2002, Vol. 58, No. 2, pp. 193-212. 
[67] Kato, S., Mutoh, I. and Shomura, M., "Collapse of Semi-rigidly Jointed Reticulated Domes with Initial Geometric Imperfections", J. Construct. Steel Research, 1998, Vol. 48, pp. 145-168.

[68] Kato, S., Kim, J.M. and Cheong, M., "A New Proportioning Method for Member Sections of Single Layer Reticulated Domes Subjected to Uniform and Nonuniform Loadings", Engineering Structures, 2003, Vol. 25, pp. 1265-1278.

[69] Liu, Y., Xu, L. and Griersonb, D.E., "Compound-element Modeling Accounting for Semi-rigid Connections and Member Plasticity", Engineering Structures, 2008, Vol. 30, pp. 1292-1307.

[70] Sekulovic, M., Nefovska-Danilovic, M., "Contribution to Transient Analysis of Inelastic Steel Frames with Semi-rigid Connections”, Engineering Structures, 2008, Vol. 30, pp. 976-989.

[71] Chiorean, C.G., "A Computer Method for Nonlinear Inelastic Analysis of 3D Semi-rigid Steel Frameworks", Engineering Structures, 2009, Vol. 31, No. 12, pp. 3016-3033.

[72] Crisfield, M.S., "A Fast Incremental Iterative Solution Procedure that Handles 'Snap Through'”, Computers \& Structures, 1981, Vol. 13, pp. 55-62.

[73] Ramm, E., "Strategies for Tracing the Nonlinear Response Near Limit Points", in : Wunderlich, W., Stein, E. and Bathe, K.J., Eds., Nonlinear Finite Element Analysis in Structural Mechanics. Springer, 1981, pp. 63-89.

[74] Crisfield, M.A., "Nonlinear Finite Element Analysis of Solids and Structures", Vol.1, Essentials, John Wiley \& Sons, 1991.

[75] Crisfield, M.A., "Nonlinear Finite Element Analysis of Solids and Structures", Vol.2, Advanced Topics, John Wiley \& Sons, 1997.

[76] Chan, S.L. and Zhou, Z.H., "Pointwise Equilibrium Polynomial Element for Nonlinear Analysis of Frames", J. Struct. Eng., ASCE, 1994, Vol. 120, pp. 1703-1717.

[77] Izzuddin, B.A., "Quartic Formulation for Elastic Beam-columns subject to Thermal Effects", J. Eng. Mech., ASCE, 1996, Vol. 122, pp. 861-71.

[78] Chan, S.L. and Zhou, Z.H., "Nonlinear Integrated Design and Analysis of Skeletal Structures by 1 Element per Member", Engineering Structures, 2000, Vol. 22, pp. 246-57.

[79] Liew, J.Y.R., Chen, H., Shanmugam, N.E. and Chen, W.F., "Improved Nonlinear Plastic Hinge Analysis of Space Frame Structures", Engineering Structures, 2000, Vol. 22, pp. 1324-1338.

[80] Hasegawa, A., Liyanage, K.K. and Nishino, F., "Non-iterative Nonlinear Analysis Scheme of Frames with Thin-walled Elastic Members", Structural Engrg./Earthquake Engrg., 1987, Vol. 4, pp. 45-55.

[81] Hodge, D.G., "Plastic Analysis of Structures", McGraw -Hill, New York, 1959.

[82] Ueda, Y., Yao, T., “The Plastic Node Method : A New Method of Plastic Analysis", Comput. Methods Appl. Mech. Engrg., 1982, Vol. 34, pp. 1089-1104.

[83] Papadrakakis, M. and Ghionis, P., "Conjugate Gradient Algorithms in Nonlinear Structural Analysis problems", Comput. Methods Appl. Mech. Engrg., 1986, Vol. 59, No. 1, pp. 11-27.

[84] Hart, J.D. and Wilson, E.L., "Simplified Earthquake Analysis of Buildings Including Site Effects", Report No.UCB/SEMM-89/23, Department of Civil Engineering, University of California, Berkeley, December, 1989. 